\title{
3 Research Suare

\section{Exceptional hydrogen evolution in acid enabled by a multi-function-site complex oxide via atomic-scale hydrogen spillover}

Jie Dai

Nanjing Tech University

Yinlong Zhu

Monash University https://orcid.org/0000-0002-9207-2452

\section{Yu Chen}

Monash University https://orcid.org/0000-0001-7882-1077

\section{Xue Wen}

Shanghai Jiao Tong University

Mingce Long

Shanghai Jiao Tong University https://orcid.org/0000-0002-5168-8330

Xinhao Wu

Nanjing Tech University

Zhiwei Hu

Max Planck Institute for Chemical Physics of Solids https://orcid.org/0000-0003-0324-2227

Daqin Guan

Nanjing Tech University https://orcid.org/0000-0001-5393-2301

\section{Xixi Wang}

Nanjing Tech University

Qian Lin

Monash University

\section{Yifei Sun}

Xiamen University

\section{Shih-Chang Weng}

National Synchrotron Radiation Research Center

Huanting Wang

Monash University https://orcid.org/0000-0002-9887-5555

Wei Zhou

Nanjing University of Technology https://orcid.org/0000-0003-0322-095X

Zongping Shao ( $\sim$ Shaozp@njtech.edu.cn )

Nanjing Tech University https://orcid.org/0000-0002-4538-4218 
Article

Keywords: hydrogen evolution reaction (HER), platinum (Pt), electrocatalysts

Posted Date: July 13th, 2021

DOI: https://doi.org/10.21203/rs.3.rs-670823/v1

License: (c) (i) This work is licensed under a Creative Commons Attribution 4.0 International License. Read Full License

Version of Record: A version of this preprint was published at Nature Communications on March 4th, 2022. See the published version at https://doi.org/10.1038/s41467-022-28843-2. 


\section{Abstract}

Improving the catalytic efficiency of platinum (Pt) for hydrogen evolution reaction (HER) is crucial for water splitting technologies, and hydrogen spillover has emerged as a new frontier in designing the binary-component Pt/support HER electrocatalysts. However, such binary catalysts always suffer from long reaction pathway, undesirable interfacial barrier, and complicated synthesis processes. Here we report a single-phase complex oxide $\mathrm{La}_{2} \mathrm{Sr}_{2} \mathrm{PtO}_{7+\delta}$ as a high-performance HER electrocatalysts in acidic media via a unique atomic-scale hydrogen spillover effect between multifunctional catalytic sites. With insights from theoretical calculations, a possible synergistic mechanism involving the hydrogen spillover channel from $\mathrm{O}_{\mathrm{La}}$ site $\rightarrow$ La-Pt bridge site $\rightarrow$ Pt site is proposed; namely, the $\mathrm{O}_{\text {La }}$ site enriches proton, the LaPt bridge site with thermo-neutral $\mathrm{H}^{\star}$ adsorption facilitates the hydrogen spillover and $\mathrm{H}_{2}$ generation, and Pt site favors the final $\mathrm{H}_{2}$ desorption. Benefiting from such unusual phenomenon, the resulting $\mathrm{La}_{2} \mathrm{Sr}_{2} \mathrm{PtO}_{7+\delta}$ exhibits an exceptional HER electrode activity with low overpotential of $13 \mathrm{mV}$ at $10 \mathrm{~mA}$ $\mathrm{cm}^{-2}$ and small Tafel slope of $22 \mathrm{mV} \mathrm{dec}{ }^{-1}$, and significantly enhanced intrinsic activity and durability than commercial Pt black catalyst.

\section{Introduction}

Accelerated exhaustion of fossil fuels accompanied with ever-increasing environmental issues has raised great concerns about the exploitation of renewable energy sources (e.g., solar and wind power) ${ }^{1,2}$. To overcome the intermittent nature of the renewable energy, an attractive prospect is to store them in the form of chemical bonds in certain molecular fuels ${ }^{3,4}$. Among various chemical fuels, hydrogen $\left(\mathrm{H}_{2}\right)$ has been pursued as the future sustainable energy alternatives to fossil fuels in view of high gravimetric energy density and carbon-free characteristics ${ }^{5-7}$. Therefore, finding a way to produce hydrogen efficiently is crucial for the future hydrogen economy. Electrochemical water splitting powered by renewable energy offers a cost-effective and promising approach for clean hydrogen production with high purity ${ }^{8-10}$. Water splitting in acidic solid polymer electrolytes is more efficient than alkaline electrolysis because it holds some notable superiority such as greater energy efficiency, higher current density, lower crossover of gases and more compact system design ${ }^{11,12}$. As the cathodic reaction in water splitting, the hydrogen evolution reaction (HER) is sluggish and requires an efficient electrocatalyst to expedite the rate. Currently, although a host of non-platinum candidate materials for HER were studied, the metallic platinum (Pt) is still considered as 'the Holy Grail' of HER electrocatalyst in acidic media with a nearly-zero onset overpotential and fast kinetics owing to its favorable hydrogen binding energy ${ }^{13,14}$. However, the natural scarcity, high cost and poor durability limit its large-scale commercial applications of water electrolyzers ${ }^{15,16}$. As a consequence, it is necessary to improve the intrinsically catalytic ability and the utilization efficiency of Pt for HER.

Hitherto, numerous efforts have been made to design Pt-based HER catalysts in acid ${ }^{17-24}$. For example, the catalytic efficiency of Pt metal could be boosted by the size ${ }^{17}$, composition ${ }^{18}$, morphology ${ }^{19}$, and 
crystal phase-engineering strategies ${ }^{20}$. Besides, hybridizing Pt with another component is also an effective way to achieve high-performance HER electrocatalysts via hydrogen spillover phenomenon ${ }^{21-24}$. Recently, hydrogen spillover opens new opportunities for improving the HER activity of binary metal/support catalysts with hydrogen-enriched Pt nanocrystals and hydrogen-deficient components, such as $\mathrm{WO}_{3-\mathrm{x}}{ }^{21}, \mathrm{SiO}_{2}{ }^{22}, \mathrm{RuCeO}_{\mathrm{x}}{ }^{23}, \mathrm{CoP}^{24}$. As schematically illustrated in Fig. 1a, hydrogen spilloverbased binary-component catalyst (HSBCC) involves three main steps: i) the strong proton $\left(\mathrm{H}^{+}\right)$adsorption on metals (e.g., Pt with $\Delta \mathrm{G}_{\mathrm{H} \text {-metal }}<0$ ), ii) the interfacial $\mathrm{H}$ diffusion and spillover from metals to supports, and iii) efficient $\mathrm{H}_{2}$ desorption on supports $\left(\Delta \mathrm{G}_{\mathrm{H} \text {-support }}>0\right){ }^{24}$. Nonetheless, considerable barriers need to be overcome for the hydrogen spillover process in HSBCC systems due to long reaction path and undesirable interfacial resistance within two components (e.g., Schottky barrier and unmatched lattice space) ${ }^{2,25-27}$. Furthermore, HSBCCs always suffer from complicated synthesis processes, which are disadvantageous for cost-effective and large-scale fabrication. In light of the short reaction path and interface-free feature in single-component catalysts ${ }^{2,25,28,29}$, the creation of atomic-level multiple catalytic sites for strong $\mathrm{H}^{+}$adsorption, thermo-neutral $\mathrm{H}$ adsorption and facile $\mathrm{H}_{2}$ desorption simultaneously in hydrogen spillover-based single-component catalyst (HSSCC) system (as illustrated in Fig. 1b), is highly desirable to boost the acidic HER activity; yet still, such single-phase catalysts have not been reported so far.

Multi-metal oxides have attracted great interest in many catalytic applications by virtue of their structural and compositional flexibility ${ }^{30-32}$. The multiple elements and variable crystal structures could endow multi-metal oxides with some unique geometrical and electronic properties, consequently tailoring the binding behavior of reaction intermediates and promoting their electrocatalytic activities ${ }^{30-32}$. Inspired by aforementioned considerations, here we demonstrate a new family of complex metal oxide prepared by a facile solid-phase reaction method, $\mathrm{La}_{2} \mathrm{Sr}_{2} \mathrm{PtO}_{7+\delta}$, as a highly active and durable HER electrocatalyst in acid media. This complex oxide crystallizes in a whexagonal structure with alternating layers of $\left[\mathrm{La}_{2} \mathrm{PtO}_{6}\right]$ containing isolated $\mathrm{Pt}^{\mathrm{IV}} \mathrm{O}_{6}$ octahedra and $\left[\mathrm{Sr}_{2} \mathrm{O}_{1+\delta}\right]$ slabs. The $\mathrm{La}_{2} \mathrm{Sr}_{2} \mathrm{PtO}_{7+\delta}$ oxide displays a remarkable HER activity with a low overpotential of $13 \mathrm{mV}$ at $10 \mathrm{~mA} \mathrm{~cm}^{-2}$ and a small Tafel slope of $22 \mathrm{mV} \mathrm{dec}^{-1}$ in $0.5 \mathrm{M} \mathrm{H}_{2} \mathrm{SO}_{4}$, superior to state-of-the-art HSBCCs and other Pt-based catalysts ever reported. In addition, the $\mathrm{La}_{2} \mathrm{Sr}_{2} \mathrm{PtO}_{7+\delta}$ shows significant enhancement in the intrinsic activity and operational durability as compared with the commercial Pt black catalyst. First-principles calculations suggest that the hydrogen adsorption at La-Pt bridge site in $\mathrm{La}_{2} \mathrm{Sr}_{2} \mathrm{PtO}_{7+\delta}$ is nearly thermo-neutral, which could serve as the mediators for favorable hydrogen spillover and accordingly result in exceptionally high activity. Specifically, a unique synergistic mechanism of multi-function catalytic sites in $\mathrm{La}_{2} \mathrm{Sr}_{2} \mathrm{PtO}_{7+\delta}$ via hydrogen spillover for HER was proposed: the $\mathrm{O}_{\mathrm{La}}$ site serves as the proton enrichment, the thermo-neutral adsorption of $\mathrm{H}^{*}$ at La-Pt bridge site benefits the hydrogen spillover and $\mathrm{H}_{2}$ generation, and Pt site favors the final $\mathrm{H}_{2}$ desorption. This work opens a new avenue for the design of high-performance HER catalysts in acid media though hydrogen spillover among multi-function-site synergy in single component. 


\section{Results}

\section{Crystal structure and morphology}

The new kind of complex oxide $\mathrm{La}_{2} \mathrm{Sr}_{2} \mathrm{PtO}_{7+\delta}$ crystallizes in a hexagonal structure containing oxidized $\mathrm{Pt}$ ion as the B-site cation. Actually, $\mathrm{La}_{2} \mathrm{Sr}_{2} \mathrm{PtO}_{7+\delta}$ is the $\mathrm{n}=2$ member of the general family of $\left[\mathrm{A}_{2}^{\prime} \mathrm{O}_{1+\delta}\right]\left[\mathrm{A}_{n} \mathrm{~B}_{n-}\right.$ ${ }_{1} \mathrm{O}_{3 n}$ ] hexagonal perovskites with $\mathrm{n}$ representing the number of $\mathrm{AO}_{3}$ successive layers ${ }^{33}$. Along the $\mathrm{c}$-axis, the structure of $\mathrm{La}_{2} \mathrm{Sr}_{2} \mathrm{PtO}_{7+\delta}$ can be presented by the uniform stacking of two $\mathrm{LaO}_{3}$ layers and one $\mathrm{Sr}_{2} \mathrm{O}_{1+\delta}$ layer (Fig. 2a). In the [ $\left.\mathrm{La}_{2} \mathrm{PtO}_{6}\right]$ slab, the Pt ions occupy the octahedral sites between the neighboring $\mathrm{LaO}_{3}$ layers to form isolated $\mathrm{PtO}_{6}$ units. The $\mathrm{La}_{2} \mathrm{Sr}_{2} \mathrm{PtO}_{7+\delta}$ oxide powder were successfully prepared by conventional solid-state synthesis, and the crystal structure was initially verified by X-ray diffraction (XRD). Rietveld refinement of the XRD pattern reveals that the $\mathrm{La}_{2} \mathrm{Sr}_{2} \mathrm{PtO}_{7+\delta}$ adopts a hexagonal structure with a space group of $R-3$, and lattice parameters of $a=b=5.7913$ (2) $\AA, c=18.1097(7)$ $\AA$ (Fig. 2b and Supplementary Table 1), which well agrees with previous study ${ }^{33}$. The phase structure was further confirmed by the selected area electron diffraction (SAED) pattern along the [-110] direction and the corresponding high-resolution transmission electron microscopy (HRTEM) image. The SAED pattern in Fig. $\mathbf{2 c}$ reflects the hexagonally arranged diffraction spots of [-110] zone axis. A lattice fringe with lattice spacing of $0.61 \mathrm{~nm}$ was seen in the HRTEM image (Fig. 2d), corresponding to the (003) plane of $\mathrm{La}_{2} \mathrm{Sr}_{2} \mathrm{PtO}_{7+\delta}$ oxide. Besides, the morphology of $\mathrm{La}_{2} \mathrm{Sr}_{2} \mathrm{PtO}_{7+\delta}$ powder was examined by scanning electron microscopy (SEM). Some chunks composed of micrometer-sized particles were observed (Supplementary Fig. 1), suggesting the bulk nature of the as-synthesized $\mathrm{La}_{2} \mathrm{Sr}_{2} \mathrm{PtO}_{7+\delta}$ oxide by solidstate reaction method. As shown in Fig. $2 \mathbf{e}$, the high-angle annular dark-field scanning transmission electron microscopy (HAADF-STEM) and elemental mapping images demonstrate the homogeneous distribution of all elements in the as-prepared $\mathrm{La}_{2} \mathrm{Sr}_{2} \mathrm{PtO}_{7+\delta}$ material. For a direct comparison in this work, commercial Pt black catalyst was also included and the pure phase structure was confirmed by XRD patterns (Supplementary Fig. 2). The Pt black catalyst has broad XRD peaks, implying nanocrystalline feature of the metallic Pt as evidenced by small nanoparticles $(\sim 5 \mathrm{~nm})$ in TEM image (Supplementary Fig. 3).

\section{Electronic structure}

X-ray photoelectron spectroscopy (XPS) and X-ray absorption spectroscopy (XAS) were carried out to explore the surface chemical state and electronic structure of $\mathrm{La}_{2} \mathrm{Sr}_{2} \mathrm{PtO}_{7+\delta}$. Figure S4 presents the full XPS spectrum of $\mathrm{La}_{2} \mathrm{Sr}_{2} \mathrm{PtO}_{7+\delta}$, which demonstrates the existence of $\mathrm{La}, \mathrm{Sr}, \mathrm{Pt}$, and $\mathrm{O}$ elements on the surface. As seen from the high-resolution Pt $4 \mathrm{f}$ core level spectra in Fig. 3a, two peaks at $74.9 \mathrm{eV}$ and 78.1 $\mathrm{eV}$ were observed, which could be ascribed to the $\mathrm{Pt} 4 \mathrm{f}_{7 / 2}$ and $\mathrm{Pt}_{4 \mathrm{f}_{5 / 2}}$ orbitals of oxidized Pt (IV) species $^{13,23,34}$. Notably, in contrast to the Pt $4 \mathrm{f}$ spectra of commercial Pt black, no signals from metallic $\mathrm{Pt}$ at $71.4 \mathrm{eV}$ and $74.7 \mathrm{eV}$ were detected, indicating the absence of metallic Pt in the $\mathrm{La}_{2} \mathrm{Sr}_{2} \mathrm{PtO}_{7+\delta}$. To further confirm the oxidation state of Pt ions in $\mathrm{La}_{2} \mathrm{Sr}_{2} \mathrm{PtO}_{7+\delta}$, X-ray absorption near-edge structure (XANES) spectra were also collected along with standard Pt foil as a reference (Fig. 3b). XANES spectrum 
at the $5 d L_{3}$ edge is highly sensitive to the valence state of $5 d$ elements: an increase of the valence state of the $5 \mathrm{~d}$ metal ion by one causes a shift of the $\mathrm{L}_{3}$ spectra by more than one eV toward higher energies ${ }^{35}$, 36. The intensity of white line peak in $\mathrm{Pt} L_{3}$-edge XANES spectra associates with the electronic transition from $2 p_{3 / 2}$ to unoccupied $5 d$ states and discloses the oxidation state of Pt species ${ }^{16,17}$. The white-line intensity of the $\mathrm{La}_{2} \mathrm{Sr}_{2} \mathrm{PtO}_{7+\delta}$ is much higher than that of the metallic Pt foil, suggesting Pt oxide species in $\mathrm{La}_{2} \mathrm{Sr}_{2} \mathrm{PtO}_{7+\delta}{ }^{16,17}$. Moreover, the white line of $\mathrm{Pt}-\mathrm{L}_{3}$ of $\mathrm{La}_{2} \mathrm{Sr}_{2} \mathrm{PtO}_{7+\delta}$ locates at about $1.5 \mathrm{eV}$ higher in energy than that of Pt foil indicating further higher oxidation state of the former. It is also well known that the extended X-ray absorption fine structure (EXAFS) is sensitive tool to uncover the local coordination of $5 \mathrm{~d}$ elements ${ }^{37,38}$. Fig. $3 \mathrm{c}$ shows the $k^{3}$-weighted Fourier transform (FT) curves at $R$ space of $\mathrm{Pt} L_{3}$-edge EXAFS spectra for $\mathrm{La}_{2} \mathrm{Sr}_{2} \mathrm{PtO}_{7+\delta}$ in comparison with the Pt foil reference. The most intense peak at $1.64 \AA$ for $\mathrm{La}_{2} \mathrm{Sr}_{2} \mathrm{PtO}_{7+\delta}$ was detected, corresponding to Pt-O bond ${ }^{17,39}$. Also, the isolated $\mathrm{PtO}_{6}$ octahedra in $\mathrm{La}_{2} \mathrm{Sr}_{2} \mathrm{PtO}_{7+\delta}$ is evidenced by the absence of the Pt-Pt coordination at $\sim 2.52 \AA$ in the first-shell region relative to $\mathrm{Pt}$ foil ${ }^{17,40}$. To visually explore the coordination conditions of $\mathrm{Pt}$, a more powerful wavelet transform (WT) analysis was performed to directly reflect the structure information in the resolution of $R$ space and $\mathrm{k}$ space. As shown in Fig. 3d, The WT intensity maximum of $\mathrm{La}_{2} \mathrm{Sr}_{2} \mathrm{PtO}_{7+\delta}$ occurs near $\mathrm{R}$ space of $1.7 \AA$ and $k$ space of $6.5 \AA^{-1}$, confirming the coordination structure of Pt-O bonds in the first coordination shell. As for Pt foil, a new WT intensity maximum near $2.7 \AA$ and $10.4 \AA^{-1}$ appears in Fig. 3e, which is associated with Pt-Pt bonding. Based on previous studies, the $5 \mathrm{~d}$ orbital of the Pt sites in a highly oxidized state can hybridize with the $\mathrm{H} 1 \mathrm{~s}$ orbital to form weak Pt-H bonds, giving rise to enhanced intrinsic activity and facile $\mathrm{H}_{2}$ evolution ${ }^{13}, 41$. Accordingly, the unique electronic structure of oxidized $\mathrm{Pt}$ sites in $\mathrm{La}_{2} \mathrm{Sr}_{2} \mathrm{PtO}_{7+\delta}$ is expected to help tailor the hydrogen binding energy on the catalyst surface and thereby improve the catalytic activity. Hydrogen temperature-programmed desorption $\left(\mathrm{H}_{2}-\mathrm{TPD}\right)$

measurements were carried out to investigate the Pt-H binding capability of $\mathrm{La}_{2} \mathrm{Sr}_{2} \mathrm{PtO}_{7+\delta}$ and $\mathrm{Pt}$ black ${ }^{42}$, 43 . In Fig. 3f, the $\mathrm{H}_{2}$ desorption process of Pt black occurs within the temperature window of $276-558{ }^{\circ} \mathrm{C}$ with a peak at $425^{\circ} \mathrm{C}$. The $\mathrm{La}_{2} \mathrm{Sr}_{2} \mathrm{PtO}_{7+\delta}$ shows lower desorption peak temperature of $356{ }^{\circ} \mathrm{C}$, indicative of the weakened hydrogen binding energy and easier $\mathrm{H}_{2}$ desorption. Combining above analysis, the $\mathrm{Pt}$ in $\mathrm{La}_{2} \mathrm{Sr}_{2} \mathrm{PtO}_{7+\delta}$ is in an oxidized state $\left(\sim \mathrm{Pt}^{4+}\right)$, which is beneficial for $\mathrm{H}_{2}$ desorption.

\section{Electrocatalytic HER performance in acid}

To evaluate the acidic HER electrocatalytic performance of $\mathrm{La}_{2} \mathrm{Sr}_{2} \mathrm{PtO}_{7+\delta}$, we conducted electrochemical measurements in $0.5 \mathrm{M} \mathrm{H}_{2} \mathrm{SO}_{4}$ solution using a standard three-electrode configuration. The commercial Pt black was also tested under identical conditions for comparison. If not specified otherwise, all potentials in this work were $i R$-corrected to remove the ohmic drop across the electrolyte and referenced to a reversible hydrogen electrode (RHE, see Supplementary Fig. 5 for calibration). As seen from the polarization curves in Fig. 4 a, the $\mathrm{La}_{2} \mathrm{Sr}_{2} \mathrm{PtO}_{7+\delta}$ exhibits a very small overpotential of $13 \mathrm{mV}$ at a current density of $-10 \mathrm{~mA} \mathrm{~cm}^{-2}$, close to that $(3 \mathrm{mV}$ ) of commercial Pt black catalyst. To examine the kinetics and 
reaction mechanism, Tafel plots were drawn in Fig. 4b. The Tafel slope for $\mathrm{La}_{2} \mathrm{Sr}_{2} \mathrm{PtO}_{7+\delta}\left(22 \mathrm{mV} \mathrm{dec}^{-1}\right)$ is smaller than that for Pt black $\left(30 \mathrm{mV} \mathrm{dec}^{-1}\right)$, implying faster HER rates. Noticeably, such a small Tafel slop value of $22 \mathrm{mV} \mathrm{dec}^{-1}$ for $\mathrm{La}_{2} \mathrm{Sr}_{2} \mathrm{PtO}_{7+\delta}$ suggests that the acidic HER electrocatalysis of the $\mathrm{La}_{2} \mathrm{Sr}_{2} \mathrm{PtO}_{7+\delta}$ catalyst may follow a different reaction mechanism to conventional Volmer-Tafel, as will be discussed below. Above electrochemical analyses (e.g., small overpotential and low Tafel slope) highlight the extraordinary electrode activity of $\mathrm{La}_{2} \mathrm{Sr}_{2} \mathrm{PtO}_{7+\delta}$ for $\mathrm{HER}$ in acidic media, although $\mathrm{La}_{2} \mathrm{Sr}_{2} \mathrm{PtO}_{7+\delta}$ is one bulk material composed of micrometer-sized particles. Such excellent HER activity of $\mathrm{La}_{2} \mathrm{Sr}_{2} \mathrm{PtO}_{7+\delta}$ is superior to that of reported HSBCCs and state-of-the-art Pt-based catalysts up to now (Fig. $\mathbf{4 c}$ and Supplementary Table 2), demonstrating that $\mathrm{La}_{2} \mathrm{Sr}_{2} \mathrm{PtO}_{7+\delta}$ ranks the top HER electrocatalyst in acidic media. It's known that two aspects (i.e., the intrinsic activity of each active site and the number of active sites) generally determine the overall catalytic activity of electrocatalysts ${ }^{44}$. To assess the intrinsic activity of $\mathrm{La}_{2} \mathrm{Sr}_{2} \mathrm{PtO}_{7+\delta}$, we further calculated the specific activity by normalizing the electrode activity to the electrochemical surface area (ECSA) and real surface area (RSA). The values of ECSA and RAS of catalysts were estimated from the hydrogen underpotential deposition $\left(\mathrm{H}_{U P D}\right)$ (Supplementary Fig. 6) and Brunner-Emmet-Teller (BET) measurements (Supplementary Fig. 7). Notably, the ECSA values of $\mathrm{La}_{2} \mathrm{Sr}_{2} \mathrm{PtO}_{7+\delta}$ and $\mathrm{Pt}$ black were determined by integrating the charge of $\mathrm{H}_{U P D}$ desorption peak in cyclic voltammogram (CV) curves according to previous studies ${ }^{45}$, 46 . As we can see in Figure $S 6$, the $\mathrm{H}_{\mathrm{UPD}}$ integrated area of $\mathrm{La}_{2} \mathrm{Sr}_{2} \mathrm{PtO}_{7+\delta}\left(1.99 \mathrm{~m}^{2} / \mathrm{g}_{\mathrm{Pt}}\right)$ is obviously smaller than that $\left(70.11 \mathrm{~m}^{2} / \mathrm{g}_{\mathrm{Pt}}\right.$, similar with previous studies $\left.{ }^{45,46}\right)$ of Pt black, which may stem from the low oxide surface area $\left(2.8 \mathrm{~m}^{2} \mathrm{~g}^{-1}\right)$ and bulk morphology of $\mathrm{La}_{2} \mathrm{Sr}_{2} \mathrm{PtO}_{7+\delta}$. Surprisingly, regardless of the electrode activity normalized to the ECSA or RSA, the $\mathrm{La}_{2} \mathrm{Sr}_{2} \mathrm{PtO}_{7+\delta}$ catalyst offers a much higher specific activity than Pt black (Fig. $4 \mathbf{d} \&$ e). For instance, at $\eta=0.05 \mathrm{~V}$, the enhancement values in specific activity normalized to the ECSA and RSA for $\mathrm{La}_{2} \mathrm{Sr}_{2} \mathrm{PtO}_{7+\delta}$ are up to about 18 and 2.2 times as compared with $\mathrm{Pt}$ black, indicative of its superior intrinsic activity towards acidic HER. Moreover, turnover frequency (TOF) values of $\mathrm{La}_{2} \mathrm{Sr}_{2} \mathrm{PtO}_{7+\delta}$ and $\mathrm{Pt}$ black were calculated to further compare their intrinsic activity, which represents the amount of $\mathrm{H}_{2}$ molecule evolving per active site per second. TOF was plotted versus potential (Fig. 4f) based on the calculated numbers of surface active sites according to the previously-reported methods (see

Supplementary Fig. 8 and Supplementary Note. 1) ${ }^{47,48}$. Remarkably, the $\mathrm{La}_{2} \mathrm{Sr}_{2} \mathrm{PtO}_{7+\delta}$ delivers an extremely high TOF value of $596 \mathrm{~s}^{-1}$ at overpotential of $0.05 \mathrm{~V}$, which is about two orders of magnitude higher than the commercial Pt black.

In addition to the catalytic activity, we also take the long-term durability of the $\mathrm{La}_{2} \mathrm{Sr}_{2} \mathrm{PtO}_{7+\delta}$ catalyst into consideration to assess its potential for practical application. For this purpose, the accelerated durability tests (ADT) by continuous cycling within HER potential window were conducted. As shown in Fig. $\mathbf{4 g}$, after 1000-cycling, the $\mathrm{La}_{2} \mathrm{Sr}_{2} \mathrm{PtO}_{7+\delta}$ exhibits only slight activity decline but Pt black suffers from obvious activity loss. For example, $\mathrm{La}_{2} \mathrm{Sr}_{2} \mathrm{PtO}_{7+\delta}$ displays a decay of only $10 \%$ whereas a nearly 5.4 -fold faster decay rate (54\%) was observed for Pt black during the period of continuous 1000-cycle operation (Fig. $4 \mathrm{~h}$ \& i). In conjunction with a series of post-HER measurements including XRD, XAS, TEM and STEM-EDS 
(Figure S9-S12), some metallic Pt species are formed on the surface, which may account for slight activity decline after 1000-cycling due to inferior activity of metallic Pt than bulk $\mathrm{La}_{2} \mathrm{Sr}_{2} \mathrm{PtO}_{7+\delta}$ component. It should be noted that short-time cycling (e.g., 10-cycling) does not lead to the activity loss and $\mathrm{Pt}$ formation of $\mathrm{La}_{2} \mathrm{Sr}_{2} \mathrm{PtO}_{7+\delta}$, as reflect by almost overlapped polarization curve with the initial one and the absence of metallic Pt peak in XRD pattern after 10-cycling. Besides, the negligible fluctuation of overpotential (@-10 mA cm${ }^{-2}$ ) was observed for $\mathrm{La}_{2} \mathrm{Sr}_{2} \mathrm{PtO}_{7+\delta}$ during $50 \mathrm{~h}$ chronopotentiometry test (Fig. 4j), which further confirms the robust operation durability for HER. Overall, the high electrode/intrinsic activity and electrochemical durability endow $\mathrm{La}_{2} \mathrm{Sr}_{2} \mathrm{PtO}_{7+\delta}$ as a promising HER electrocatalyst candidate for future practical application in acidic water electrolysis.

\section{DFT calculations}

To gain atomic-scale insight into the origin of the exceptional intrinsic activity of $\mathrm{La}_{2} \mathrm{Sr}_{2} \mathrm{PtO}_{7+\delta}$ for $\mathrm{HER}$ in acid, density functional theory (DFT) calculations were carried out. Based on prior structural data and the analysis of HRTEM and SAED, (001) surface slab models with different terminations of $\mathrm{La}_{2} \mathrm{Sr}_{2} \mathrm{PtO}_{7+\delta}$ and the optimized structures are shown in Fig. 5a. Generally, the acidic HER process involves a three-state diagram with an initial proton $\left(\mathrm{H}^{+}\right)$, an intermediate adsorbed $\mathrm{H}^{\star}$ and a final $\mathrm{H}_{2}$ state, and the hydrogen adsorption Gibbs free energy $\left(\Delta \mathrm{G}_{\mathrm{H}^{*}}\right)$ is taken as a commonly-accepted descriptor for accessing the intrinsic activity of electrocatalysts towards acid $\mathrm{HER}^{49,50}$. According to the Sabatier principle, the thermo-neutral active sites with an optimal $\left|\Delta G_{H^{*}}\right|$ value close to zero can facilely promote the adsorption and desorption process during $\mathrm{HER}^{25,51}$. Fig. $\mathbf{5 b}$ shows the free energy diagram of $\mathrm{La}_{2} \mathrm{Sr}_{2} \mathrm{PtO}_{7+\delta}$ on all the possible sites at the terminations of Pt-O-La, La-O and Sr-O along with Pt (111) metal as a reference. The $\Delta \mathrm{G}_{\mathrm{H}^{\star}}$ values on $\mathrm{O}_{\mathrm{La}}, \mathrm{O}_{\mathrm{Sr}}$ and $\mathrm{Pt}$ sites for $\mathrm{La}_{2} \mathrm{Sr}_{2} \mathrm{PtO}_{7+\delta}$ are -1.11, -2.31 and 1.96 $\mathrm{eV}$, respectively, indicating that the $\mathrm{H}^{\star}$ adsorption is either too strong or too weak. Impressively, the calculated $\mathrm{G}_{\mathrm{H}^{*}}$ for the unique La-Pt bridge site is $0.11 \mathrm{eV}$, an optimal value close to a thermo-neutral state even exceeding that $(-0.16 \mathrm{eV})$ for the state-of-art Pt (111) surface, suggesting the hydrogen adsorption is neither too strong nor too weak.

As reported before, hydrogen spillover has been an efficient strategy to boost the intrinsic HER activity of the binary-component electrocatalysts ${ }^{21-24}$. These hydrogen spillover-based binary-component catalysts (HSBCCs) generally consist of one hydrogen-enriched component with a negative $\Delta \mathrm{G}_{\mathrm{H}^{*}}$ value and one hydrogen-poor component with a positive $\Delta \mathrm{G}_{\mathrm{H}^{*}}$ value, and hydrogen spillover takes place from the surface with $\Delta_{\mathrm{GH} \text {-negative }}$ to the surface with $\Delta_{\mathrm{GH} \text {-positive }}{ }^{23,24}$. When a single-component catalyst contains more than one kind of catalytic site, the hydrogen spillover effect between different sites may also happen and can affect the overall catalytic activity. With regard to single-component $\mathrm{La}_{2} \mathrm{Sr}_{2} \mathrm{PtO}_{7+\delta}$ catalyst, the $\mathrm{H}^{\star}$ preferentially adsorbs at $\mathrm{O}_{\mathrm{La}}$ site with $\Delta \mathrm{G}_{\mathrm{H}^{*}}$ value of $-1.11 \mathrm{eV}$ near to the thermo-neutral La-Pt bridge site, suggesting significant proton trapping at $\mathrm{O}_{\mathrm{La}}$ site which functions as hydrogen-enriched "component". Conversely, the $\mathrm{H}^{*}$ exhibits weak adsorption on the Pt site (also around the La-Pt bridge site) with $\Delta G_{H^{*}}$ value of $1.96 \mathrm{eV}$, indicating Pt site with high oxidation state resembles the hydrogen-poor 
"component" and is advantageous for $\mathrm{H}_{2}$ desorption. More importantly, the thermo-neutral La-Pt bridge site can serve as the mediator for favorable hydrogen spillover, similar to the interface site in the conventional HSBCCs. Thus, with the steadily weakened adsorption of $\mathrm{H}^{*}$, a feasible channel for the hydrogen spillover from $\mathrm{O}_{\mathrm{La}}$ site $\rightarrow \mathrm{La}-\mathrm{Pt}$ bridge site $\rightarrow \mathrm{Pt}$ site is formed on the $\mathrm{La}_{2} \mathrm{Sr}_{2} \mathrm{PtO}_{7+\delta}$ catalyst (Fig. 5c). Noticeable, the interface-free feature and short reaction distance within the crystal lattice on singlephase $\mathrm{La}_{2} \mathrm{Sr}_{2} \mathrm{PtO}_{7+\delta}$ catalyst is beneficial for minimizing the kinetic barrier for hydrogen spillover ${ }^{52,53}$, somewhat analogous to the reported metal alloy system with low hydrogen spillover barrier ${ }^{54-57}$. Based on these DFT results, a possible HER catalytic mechanism on $\mathrm{La}_{2} \mathrm{Sr}_{2} \mathrm{PtO}_{7+\delta}$ in acidic media via multifunction catalytic sites induced atomic-scale hydrogen spillover was proposed, as schematically illustrated in Fig. 5d. Namely, the $\mathrm{O}_{\mathrm{La}}$ site serves as the proton enrichment, the thermo-neutral adsorption of $\mathrm{H}^{*}$ at La-Pt bridge site benefits the hydrogen spillover and $\mathrm{H}_{2}$ generation, and $\mathrm{Pt}$ site favors the final $\mathrm{H}_{2}$ desorption. In addition, the hydrogen spillover effect could be also verified by Tafel slope and $\mathrm{pH}-$ dependent experiments. The Tafel slope of $\mathrm{La}_{2} \mathrm{Sr}_{2} \mathrm{PtO}_{7+\delta}$ catalyst is only $22 \mathrm{mV} \mathrm{dec}^{-1}$, which is evidently lower than the value $\left(30 \mathrm{mV} \mathrm{dec}^{-1}\right)$ via conventional Volmer-Tafel mechanism, implying a hydrogen spillover-involving mechanism as also reported before ${ }^{58-60}$. This reaction mechanism was further supported by the $\mathrm{pH}$ dependent relation of HER (Figure S13 and Fig. 5e). The reaction order of 1.52 for the $\mathrm{La}_{2} \mathrm{Sr}_{2} \mathrm{PtO}_{7+\delta}$ catalyst is close to the theoretical value of 2 and similar with the reaction orders of the previously HSBCCs ${ }^{58-60}$.

\section{Discussion}

In summary, we have successfully synthesized a single-phase complex oxide La2Sr2Pt07+ $\delta$ with exceptional HER performance in acid medium via a facile and scalable solid-state reaction method. The La2Sr2Pt07+ $\delta$ displays an outstanding HER activity with an ultralow overpotential of $13 \mathrm{mV}$ at a current density of $10 \mathrm{~mA} \mathrm{~cm}-2$ and a small Tafel slope of $22 \mathrm{mV} \mathrm{dec}-1$ in $0.5 \mathrm{M} \mathrm{H} 2 \mathrm{SO} 4$ solution, surpassing state-of-the-art Pt-based catalysts and hydrogen spillover-based binary-component catalysts ever reported. Besides, significant intrinsic activity and durability enhancement were observed for

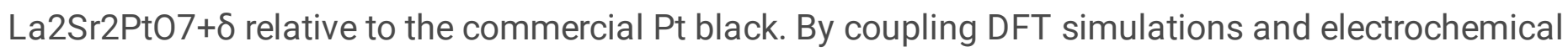
measurements, the high HER catalytic activity of La2Sr2PtO7+ $\delta$ in acid possibly results from an unusual atomic-scale hydrogen spillover effect between multiple catalytic sites, whereby OLa sites capture proton, adsorbed proton facilely diffuses from OLa sites to Pt sites via thermoneutral La-Pt bridges, and eventually as-formed $\mathrm{H} 2$ favorably releases on Pt sites. Our proof-of-concept investigations not only provides the atomic-level insight into the hydrogen spillover within La2Sr2Pt07+ $\delta$ for acidic HER, but also open a new avenue for the design of advanced electrocatalysts via constructing multifunctional catalytic sites.

\section{Methods}

\section{Catalyst synthesis}


$\mathrm{La}_{2} \mathrm{Sr}_{2} \mathrm{PtO}_{7+\delta}$ catalyst was synthesized via the traditional solid-phase reaction method. Firstly, stoichiometric amounts of $\mathrm{La}_{2} \mathrm{O}_{3}, \mathrm{SrCO}_{3}$, and $\mathrm{Pt}$ were weighed and mixed in ethanol and water under the rotation speed of $400 \mathrm{rpm}$ for $1 \mathrm{~h}$ through the high-energy ball-milling (Planetary Mono Mill, Pulverisette 6, Fritsch). Then the homogeneously dispersed mixture was dried and finally calcined at $1100{ }^{\circ} \mathrm{C}$ in air for $10 \mathrm{~h}$ to obtain the resultant catalyst powders.

\section{Characterizations}

XRD patterns were measured using a Rigaku Smartlab diffractometer operating at $40 \mathrm{kV}$ with filtered $\mathrm{Cu}$ Ka radiation. The Rietveld refinements were revealed using DIFFRAC plus Topas 4.2 software. SEM images were recorded through a scanning-electron microscope equipped with the scanning-electron microanalyzer (Hitachi S-4800). The HRTEM images were obtained utilizing the electron microscope (FEI Tecnai G2 F20) operating at $200 \mathrm{kV}$. STEM image and elemental mapping images were obtained using Tecnai F20 SuperTwin operating at 200 kV. Nitrogen adsorption-desorption isotherms were recorded on BELSORP II. Pt4f spectra were acquired on X-ray photoelectron spectroscopy (Perkin Elmer PHI 1600 ECSA system). X-ray absorption near edge structure (XANES) and the extended X-ray absorption fine structure (EXAFS) spectra were determined at the BL 07A beamline of the National Synchrotron Radiation Research Center (NSRRC) in Taiwan. All samples were pretreated via cutting pellets in an ultrahigh vacuum chamber to obtain a clean surface. Hydrogen temperature programmed desorption $\left(\mathrm{H}_{2}-\mathrm{TPD}\right)$ experiments were performed on Chembet Pulsar (Quantachrome Instruments, USA). $50 \mathrm{mg}$ of sample was pre-treated at $200^{\circ} \mathrm{C}$ for $3 \mathrm{~h}$ in hydrogen atmosphere and then was cleaned with argon gas flow at $50^{\circ} \mathrm{C}$ for 30 min to remove weakly adsorbed $\mathrm{H}_{2}$. TPD process was performed by heating the sample from $50{ }^{\circ} \mathrm{C}$ to $800{ }^{\circ} \mathrm{C}$ at a ramp rate of $2.5^{\circ} \mathrm{C} \mathrm{min}-1$ under argon atmosphere.

\section{Electrochemical Measurements}

HER measurements in acid media were conducted in a standard three-electrode electrochemical cell (Pine Research Instrumentation) in an RDE configuration using a CHI 760E electrochemistry workstation. Catalysts cast on $\mathrm{RDE}$ ( $5 \mathrm{~mm}$ in diameter), graphite rod, and $\mathrm{Ag} \mid \mathrm{AgCl}(3.5 \mathrm{M} \mathrm{KCl})$ were used as the working electrode, counter electrode, and reference electrode, respectively. Working electrodes for HER measurements were prepared by a controlled drop-casting method, in accordance with the previous works. ${ }^{2,49}$ The mass loading of oxide catalysts and Pt black on the RDE is $\sim 0.232$ and $0.058 \mathrm{mg} \mathrm{cm}^{-2}$, respectively. Linear sweep voltammetry (LSV) was recorded at $5 \mathrm{mV} \mathrm{s}^{-1}$ at the rotation of $2400 \mathrm{rpm}$ in Arsaturated $0.5 \mathrm{M} \mathrm{H}_{2} \mathrm{SO}_{4}$. Tafel slopes were determined by plotting the overpotential versus the logarithm of current density $(\log |j|)$. CV curves involving in the $\mathrm{H}_{\text {upd }}$ adsorption/desorption peak were obtained in $\mathrm{N}_{2}{ }^{-}$ saturated $0.5 \mathrm{M} \mathrm{H}_{2} \mathrm{SO}_{4}$ solution with potential window between $0.05 \mathrm{~V}$ and $1.1 \mathrm{~V}$ vs. RHE and a sweep rate of $100 \mathrm{mV} \mathrm{s}^{-1}$. The ECSA was derived from the $\mathrm{H}_{\text {upd }}$ desorption peak (0.03-0.35 V) area normalized by the total mass of the Pt element. Accelerated durability test (ADT) of catalysts was conducted through continuous potential cycling ranged from 0 to $-0.4 \mathrm{~V}$ vs. $\mathrm{Ag} \mid \mathrm{AgCl}$ for 1000 cycles at a scan rate of $100 \mathrm{mV}$ 
$\mathrm{s}^{-1}$. The chronopotentiometry tests were performed at a constant cathodic current density of $10 \mathrm{~mA} \mathrm{~cm}-2$ to explore the durability of the electrocatalysts.

\section{Computational methods}

All first-principle calculations were performed using density functional theory (DFT) implemented in the Vienna Ab initio Simulation Package (VASP). The projector augmented wave (PAW) pseudo potentials with the Perdew-Burke-Enrnzerhof (PBE) functional were used. The cutoff of kinetic energy was set as $500 \mathrm{eV}$. $\mathrm{La}_{2} \mathrm{Sr}_{2} \mathrm{PtO}_{7}$ bulk with R-3 space group was built for lattice structure optimization. Monkhorst-Pack $7 \times 7 \times 2 k$-point mesh was used during the structure relaxation. (001) surface slab models with different terminations were cleaved from the optimized bulk lattice to investigate HER on surface. A $15 \AA$-thick vacuum layer was added to the surface in the $z$ direction. Half layers on the bottom were fixed to mimic bulk arrangements, while other layers were fully relaxed to represent surface features. The first Brillouin zone of the slab model was samples with a $5 \times 5 \times 1 k$-point grid. All calculations were performed in a spinpolarized fashion. The force and energy convergence criteria were set to $0.02 \mathrm{eV} \AA^{-1}$ and $10^{-5} \mathrm{e} \AA$, respectively. Zero-point energy and entropy corrections were introduced for Gibbs energy calculations.

\section{Declarations}

\section{Data availability}

The data that support the findings of this study are available from the corresponding authors upon request.

\section{Acknowledgements}

This work was financially supported by National Natural Science Foundation of China under No. 21878158 and 21576135, and Priority Academic Program Development (PAPD) of Jiangsu Higher Education Institutions. Dr. Z. Hu acknowledges the support from the Max Planck-POSTECH-Hsinchu Center for Complex Phase Materials, and Dr. Y. Zhu acknowledges the Australian Research Council (Discovery Early Career Researcher Award No. DE190100005). We also acknowledge the use of instruments and scientific and technical assistance at the Monash Centre for Electron Microscopy, a Node of Microscopy Australia, and the help from Dr. Hassan A. Tahini in DFT calculations.

\section{Author contributions}

J.D., Y.Z. and Z.S. conceived and designed the research. J.D. conducted characterizations and electrochemical measurements. Y.C., X.W. and M.L. performed TEM characterizations. H.W., Z.H. and S.W performed XAS characterizations. D.G. performed XRD refinements. Y.Z., X.W. and Q.L. was involved in the structural and electrochemical analysis. Y.S. was involved in the DFT calculations. All authors discussed and analyzed the data. D.J., Y.Z., H.W., W.Z. and Z.S. co-wrote the manuscript. 
Supplementary Information accompanies this paper on http://www.nature.com/ naturecommunications

Competing interest: The authors declare no competing interests.

\section{References}

1. Podjaski, F. et al. Rational strain engineering in delafossite oxides for highly efficient hydrogen evolution catalysis in acidic media. Nat. Catal. 3, 55-63 (2019).

2. Dai, J. et al. Single-phase perovskite oxide with super-exchange induced atomic-scale synergistic active centers enables ultrafast hydrogen evolution. Nat. Commun. 11, 5657 (2020).

3. She, Z. W. et al. Two-dimensional molybdenum carbide (MXene) as an efficient electrocatalyst for hydrogen evolution. ACS Energy Lett. 1, 589-594 (2016).

4. Chen, X., Jin, X., Ling, X. \& Wang, Y. Indirect integration of thermochemical energy storage with the recompression supercritical $\mathrm{CO}_{2}$ Brayton cycle. Energy 209, 118452 (2020).

5. Wang, Z., Li, M., Yu, J., Ge, X., Liu, Y. \& Wang, W. Low-iridium-content IrNiTa metallic glass films as intrinsically active catalysts for hydrogen evolution reaction. Adv. Mater. 32, e1906384 (2020).

6. Cheng, L. et al. Ultrathin $\mathrm{WS}_{2}$ nanoflakes as a high-performance electrocatalyst for the hydrogen evolution reaction. Angew. Chem. Int. Ed. 53, 7860-7863 (2014).

7. Zhu, Y., Lin, Q., Zhong, Y., Tahini, H., Shao, Z. \& Wang, H. Metal oxide-based materials as an emerging family of hydrogen evolution electrocatalysts. Energy Environ. Sci. 13, 3361-3392 (2020).

8. Reier, T., Nong. H. N., Teschner, D., Schlögl, R. \& Strasser, P. Electrocatalytic oxygen evolution reaction in acidic environments - reaction mechanisms and catalysts. Adv. Energy Mater. 7, (2017).

9. Kibsgaard, J. \& Jaramillo, T. F. Molybdenum phosphosulfide: an active, acid-stable, earth-abundant catalyst for the hydrogen evolution reaction. Angew. Chem. Int. Ed. 53, 14433-14437 (2014).

10. Zhu, Y. et al. Tailored brownmillerite oxide catalyst with multiple electronic functionalities enables ultrafast water oxidation. Chem. Mater. DOI: 10.1021/acs.chemmater.1c01292 (2021).

11. Han, N. et al. Nitrogen-doped tungsten carbide nanoarray as an efficient bifunctional electrocatalyst for water splitting in acid. Nat. Commun. 9, 924 (2018).

12. Kucernak, A. R. J. \& Naranammalpuram Sundaram, V. N. Nickel phosphide: the effect of phosphorus content on hydrogen evolution activity and corrosion resistance in acidic medium. J. Mater. Chem. A 2, 17435-17445 (2014). 
13. Cheng, X. et al. Highly active, stable oxidized platinum clusters as electrocatalysts for the hydrogen evolution reaction. Energy Environ. Sci. 10, 2450-2458 (2017).

14. Su, J., Yang, Y., Xia, G., Chen, J., Jiang, P. \& Chen, Q. Ruthenium-cobalt nanoalloys encapsulated in nitrogen-doped graphene as active electrocatalysts for producing hydrogen in alkaline media. Nat.

Commun. 8, 14969 (2017).

15. Li, Y. et al. Local atomic structure modulations activate metal oxide as electrocatalyst for hydrogen evolution in acidic water. Nat. Commun. 6, 8064 (2015).

16. Zheng, X. et al. Multifunctional active-center-transferable platinum/lithium cobalt oxide heterostructured electrocatalysts towards superior water splitting. Angew. Chem. Int. Ed. 59, 14533-14540 (2020).

17. Liu, D. et al. Atomically dispersed platinum supported on curved carbon supports for efficient electrocatalytic hydrogen evolution. Nat. Energy 4, 512-518 (2019).

18. Kobayashi, D. et al. Significant enhancement of hydrogen evolution reaction activity by negatively charged Pt through light doping of W. J. Am. Chem. Soc. 142, 17250-17254 (2020).

19. Cao, Z. et al. Platinum-nickel alloy excavated nano-multipods with hexagonal close-packed structure and superior activity towards hydrogen evolution reaction. Nat. Commun. 8, 15131 (2017).

20. Xu, G-R. et al. Polyallylamine-functionalized platinum tripods: enhancement of hydrogen evolution reaction by proton carriers. ACS Catal. 7, 452-458 (2016).

21. Park, J. et al. Investigation of the support effect in atomically dispersed $\mathrm{Pt}$ on $\mathrm{WO}_{3-\mathrm{x}}$ for utilization of Pt in the hydrogen evolution reaction. Angew. Chem. Int. Ed. 58, 16038-16042 (2019).

22. Esposito. D. V., Levin, I., Moffat, T. P. \& Talin, A. A. $\mathrm{H}_{2}$ evolution at Si-based metal-insulatorsemiconductor photoelectrodes enhanced by inversion channel charge collection and $\mathrm{H}$ spillover. $\mathrm{Nat}$. Mater. 12, 562-568 (2013).

23. Liu, T., Gao, W., Wang, Q., Dou, M., Zhang, Z. \& Wang, F. Selective loading of atomic platinum on a $\mathrm{RuCeO}_{\mathrm{x}}$ support enables stable hydrogen evolution at high current densities. Angew. Chem. Int. Ed. 59, 20423-20427 (2020).

24. Li, J. et al. Ethylene-glycol ligand environment facilitates highly efficient hydrogen evolution of $\mathrm{Pt} / \mathrm{CoP}$ through proton concentration and hydrogen spillover. Energy Environ. Sci. 12, 2298-2304 (2019).

25. Guan, D. et al. Searching general sufficient-and-necessary conditions for ultrafast hydrogen-evolving electrocatalysis. Adv. Funct. Mater. 29, 1900704 (2019). 
26. Wang, P., Jiang, K., Wang, G., Yao, J. \& Huang, X. Phase and interface engineering of platinum-nickel nanowires for efficient electrochemical hydrogen evolution. Angew. Chem. Int. Ed. 55, 12859-12863 (2016).

27. Wang, Y., Chen, L., Yu, X., Wang, Y. \& Zheng, G. Superb alkaline hydrogen evolution and simultaneous electricity generation by Pt-decorated $\mathrm{Ni}_{3} \mathrm{~N}$ nanosheets. Adv. Energy Mater. 7, 1601390 (2017).

28. Zhang, L. et al. N-modified NiO surface for superior alkaline hydrogen evolution. ChemSusChem 11, 1020-1024 (2018).

29. Zhao, D. et al. Synergistically interactive pyridinic-N-MoP sites: identified active centers for enhanced hydrogen evolution in alkaline solution. Angew. Chem. Int. Ed. 59, 8982-8990 (2020).

30. Grimaud, A. et al. Activation of surface oxygen sites on an iridium-based model catalyst for the oxygen evolution reaction. Nat. Energy 2, 16189 (2016).

31. Miao, X., Zhang, L., Wu, L., Hu, Z., Shi, L. \& Zhou, S. Quadruple perovskite ruthenate as a highly efficient catalyst for acidic water oxidation. Nat. Commun. 10, 3809 (2019).

32. Zhu, Y. et al. Boosting oxygen evolution reaction by creating both metal ion and lattice-oxygen active sites in a complex oxide. Adv. Mater. 32, 1905025 (2020).

33. Ebbinghaus, S. G., Erztoument, C. \& Marozau, I. $\mathrm{Ln}_{2} \mathrm{Sr}_{2} \mathrm{PtO}_{7+\delta}(\mathrm{Ln}=\mathrm{La}, \mathrm{Pr}$, and Nd): three new Ptcontaining $\left[\mathrm{A}_{n} \mathrm{~B}_{n-1} \mathrm{O}_{3 n}\right]$-type hexagonal perovskites. J. Solid. State. Chem. 180, 3393-3400 (2007).

34. Wang, Z. et al. A platinum oxide decorated amorphous cobalt oxide hydroxide nanosheet array towards alkaline hydrogen evolution. J. Mater. Chem. A 6, 3864-3868 (2018).

35. Agrestini, S. et al. Nature of the magnetism of iridium in the double perovskite $\mathrm{Sr}_{2} \mathrm{ColrO}_{6}$. Phys. Rev. $B$ 100, 014443 (2019).

36. Chen, J. et al. Enhanced magnetization of the highest- $T_{C}$ ferrimagnetic oxide $\mathrm{Sr}_{2} \mathrm{CrOsO}_{6}$. Phys. Rev. $B$ 102,184418 (2020).

37. Zhu, Y. et al. Single-atom in-doped subnanometer Pt nanowires for simultaneous hydrogen generation and biomass upgrading. Adv. Funct. Mater. 30, 2004310 (2020).

38. $\mathrm{Pi}, \mathrm{Y}$. et al. Selective surface reconstruction of a defective iridium-based catalyst for high-efficiency water splitting. Adv. Funct. Mater. 30, 2004375 (2020).

39. Zhuang, L. et al. Defect-induced Pt-Co-Se coordinated sites with highly asymmetrical electronic distribution for boosting oxygen-involving electrocatalysis. Adv. Mater. 31, 1805581 (2019). 
40. Lu, F. et al. Engineering platinum-oxygen dual catalytic sites via charge transfer towards highefficient hydrogen evolution. Angew. Chem. Int. Ed. 59, 17712 (2020).

41. Cheng, N. et al. Platinum single-atom and cluster catalysis of the hydrogen evolution reaction. Nat. Commun. 7, 13638 (2016).

42. Sheng, W. et al. Non-precious metal electrocatalysts with high activity for hydrogen oxidation reaction in alkaline electrolytes. Energy Environ. Sci. 7, 1719-1724 (2014).

43. Pan, Y. et al. Cobalt nickel phosphide nanoparticles decorated carbon nanotubes as advanced hybrid catalysts for hydrogen evolution. J. Mater. Chem. A 4, 14675-14686 (2016).

44. She, Z. W, Kibsgaard, J., Dickens, C. F, Chorkendorff, I., Nørskov, J. K. \& Jaramillo, T. F. Combining theory and experiment in electrocatalysis: insights into materials design. Science 355, eaad4998 (2017).

45. Lim, B. et al. Pd-Pt bimetallic nanodendrites with high activity for oxygen reduction. Science 324, 1302 (2009).

46. Li, M. et al. Ultrafine Jagged platinum nanowires enable ultrahigh mass activity for the oxygen reduction reaction. Science 354, 1414 (2016).

47. Kibsgaard, J. et al. Designing an improved transition metal phosphide catalyst for hydrogen evolution using experimental and theoretical trends. Energy Environ. Sci. 8, 3022-3029 (2015).

48. Mahmood, J. et al. An efficient and pH-universal ruthenium-based catalyst for the hydrogen evolution reaction. Nat. Nanotech. 12, 441-446 (2017).

49. Zhu, Y. et al. Unusual synergistic effect in layered Ruddlesden-Popper oxide enables ultrafast hydrogen evolution. Nat. Commun. 10, 149 (2019).

50. Yang, Y. et al. O-coordinated W-Mo dual-atom catalyst for pH-universal electrocatalytic hydrogen evolution. Sci. Adv. 6, eaba6586 (2020).

51. Zhou, Y. et al. Enhanced performance of in-plane transition metal dichalcogenides monolayers by configuring local atomic structures. Nat. Commun. 11, 2253 (2020).

52. Xiong, M. et al. In situ tuning of electronic structure of catalysts using controllable hydrogen spillover for enhanced selectivity. Nat. Commun. 11, 4773 (2020).

53. Sha, X., Chen, L., Cooper, A. C., Pez, G. P \& Cheng, H. Hydrogen absorption and diffusion in bulk a$\mathrm{MoO}_{3}$. J. Phys. Chem. C113, 11399-11407 (2009).

54. Marcinkowski, M. D. et al. Controlling a spillover pathway with the molecular cork effect. Nat. Mater. 12, 523-528 (2013). 
55. Shen, F. et al. Bimetallic iron-iridium alloy nanoparticles supported on nickel foam as highly efficient and stable catalyst for overall water splitting at large current density. Appl. Catal. B: Environ. 278, 119327 (2020).

56. Tierney, H. L., Baber, A. E., Kitchin, J. R. \& Sykes, E. C. H. Hydrogen dissociation and spillover on individual isolated palladium atoms. Phys. Rev. Lett. 103, 246102 (2009).

57. Baber, A. E., Tierney, H. L., Lawton, T. J. \& Sykes, E. C. H. An atomic-scale view of palladium alloys and their ability to dissociate molecular hydrogen. ChemCatChem 3, 607-614 (2011).

58. Zhu, L. et al. A rhodium/silicon co-electrocatalyst design concept to surpass platinum hydrogen evolution activity at high overpotentials. Nat. Commun. 7, 12272 (2016).

59. Cheng, Y., Lu, S., Liao, F., Liu, L., Li, Y. \& Shao, M. Rh/MoS 2 nanocomposite catalysts with Pt-like activity for hydrogen evolution reaction. Adv. Funct. Mater. 27, 1700359 (2017).

60. Sheng, M. et al. Approaching the volcano top: iridium/silicon nanocomposites as efficient electrocatalysts for the hydrogen evolution reaction. ACS Nano 13, 2786-2794 (2019).

, Nong. H. N., Teschner, D., Schlögl, R. \& Strasser, P. Electrocatalytic oxygen evolution reaction in acidic environments - reaction mechanisms and catalysts. Adv. Energy Mater. 7, (2017).

- Kibsgaard, J. \& Jaramillo, T. F. Molybdenum phosphosulfide: an active, acid-stable, earth-abundant catalyst for the hydrogen evolution reaction. Angew. Chem. Int. Ed. 53, 14433-14437 (2014).

- Zhu, Y. et al. Tailored brownmillerite oxide catalyst with multiple electronic functionalities enables ultrafast water oxidation. Chem. Mater. DOI: 10.1021/acs.chemmater.1c01292 (2021).

- Han, N. et al. Nitrogen-doped tungsten carbide nanoarray as an efficient bifunctional electrocatalyst for water splitting in acid. Nat. Commun. 9, 924 (2018).

- Kucernak, A. R. J. \& Naranammalpuram Sundaram, V. N. Nickel phosphide: the effect of phosphorus content on hydrogen evolution activity and corrosion resistance in acidic medium. J. Mater. Chem. A 2, 17435-17445 (2014).

- Cheng, X. et al. Highly active, stable oxidized platinum clusters as electrocatalysts for the hydrogen evolution reaction. Energy Environ. Sci. 10, 2450-2458 (2017).

- Su, J., Yang, Y., Xia, G., Chen, J., Jiang, P. \& Chen, Q. Ruthenium-cobalt nanoalloys encapsulated in nitrogen-doped graphene as active electrocatalysts for producing hydrogen in alkaline media. Nat. Commun. 8, 14969 (2017).

- Li, Y. et al. Local atomic structure modulations activate metal oxide as electrocatalyst for hydrogen evolution in acidic water. Nat. Commun. 6, 8064 (2015).

- Zheng, X. et al. Multifunctional active-center-transferable platinum/lithium cobalt oxide heterostructured electrocatalysts towards superior water splitting. Angew. Chem. Int. Ed. 59, 1453314540 (2020). 
- Liu, D. et al. Atomically dispersed platinum supported on curved carbon supports for efficient electrocatalytic hydrogen evolution. Nat. Energy 4, 512-518 (2019).

- Kobayashi, D. et al. Significant enhancement of hydrogen evolution reaction activity by negatively charged Pt through light doping of W. J. Am. Chem. Soc. 142, 17250-17254 (2020).

- Cao, Z. et al. Platinum-nickel alloy excavated nano-multipods with hexagonal close-packed structure and superior activity towards hydrogen evolution reaction. Nat. Commun. 8, 15131 (2017).

- Xu, G-R. et al. Polyallylamine-functionalized platinum tripods: enhancement of hydrogen evolution reaction by proton carriers. ACS Catal. 7, 452-458 (2016).

- Park, J. et al. Investigation of the support effect in atomically dispersed Pt on $\mathrm{WO}_{3-\mathrm{x}}$ for utilization of Pt in the hydrogen evolution reaction. Angew. Chem. Int. Ed. 58, 16038-16042 (2019).

- Esposito. D. V., Levin, I., Moffat, T. P. \& Talin, A. A. $\mathrm{H}_{2}$ evolution at Si-based metal-insulatorsemiconductor photoelectrodes enhanced by inversion channel charge collection and $\mathrm{H}$ spillover. $\mathrm{Nat}$. Mater. 12, 562-568 (2013).

- Liu, T., Gao, W., Wang, Q., Dou, M., Zhang, Z. \& Wang, F. Selective loading of atomic platinum on a $\mathrm{RuCeO}_{\mathrm{x}}$ support enables stable hydrogen evolution at high current densities. Angew. Chem. Int. Ed. 59, 20423-20427 (2020).

- $\mathrm{Li}$, J. et al. Ethylene-glycol ligand environment facilitates highly efficient hydrogen evolution of Pt/CoP through proton concentration and hydrogen spillover. Energy Environ. Sci. 12, 2298-2304 (2019).

- Guan, D. et al. Searching general sufficient-and-necessary conditions for ultrafast hydrogen-evolving electrocatalysis. Adv. Funct. Mater. 29, 1900704 (2019).

- Wang, P., Jiang, K., Wang, G., Yao, J. \& Huang, X. Phase and interface engineering of platinum-nickel nanowires for efficient electrochemical hydrogen evolution. Angew. Chem. Int. Ed. 55, 12859-12863 (2016).

- Wang, Y., Chen, L., Yu, X., Wang, Y. \& Zheng, G. Superb alkaline hydrogen evolution and simultaneous electricity generation by Pt-decorated $\mathrm{Ni}_{3} \mathrm{~N}$ nanosheets. Adv. Energy Mater. 7, 1601390 (2017).

- Zhang, L. et al. N-modified NiO surface for superior alkaline hydrogen evolution. ChemSusChem 11, 1020-1024 (2018).

- Zhao, D. et al. Synergistically interactive pyridinic-N-MoP sites: identified active centers for enhanced hydrogen evolution in alkaline solution. Angew. Chem. Int. Ed. 59, 8982-8990 (2020).

- Grimaud, A. et al. Activation of surface oxygen sites on an iridium-based model catalyst for the oxygen evolution reaction. Nat. Energy 2, 16189 (2016).

- Miao, X., Zhang, L., Wu, L., Hu, Z., Shi, L. \& Zhou, S. Quadruple perovskite ruthenate as a highly efficient catalyst for acidic water oxidation. Nat. Commun. 10, 3809 (2019).

- Zhu, Y. et al. Boosting oxygen evolution reaction by creating both metal ion and lattice-oxygen active sites in a complex oxide. Adv. Mater. 32, 1905025 (2020).

- Ebbinghaus, S. G., Erztoument, C. \& Marozau, I. $\mathrm{Ln}_{2} \mathrm{Sr}_{2} \mathrm{PtO}_{7+\delta}(\mathrm{Ln}=\mathrm{La}$, Pr, and Nd): three new Ptcontaining $\left[A_{n} B_{n-1} O_{3 n}\right]$-type hexagonal perovskites. J. Solid. State. Chem. 180, 3393-3400 (2007). 
- Wang, Z. et al. A platinum oxide decorated amorphous cobalt oxide hydroxide nanosheet array towards alkaline hydrogen evolution. J. Mater. Chem. A 6, 3864-3868 (2018).

- Agrestini, S. et al. Nature of the magnetism of iridium in the double perovskite $\mathrm{Sr}_{2} \mathrm{ColrO}_{6}$. Phys. Rev. $B$ 100, 014443 (2019).

- Chen, J. et al. Enhanced magnetization of the highest-TC ferrimagnetic oxide $\mathrm{Sr}_{2} \mathrm{CrOsO}_{6}$. Phys. Rev. $B$ 102,184418 (2020).

- Zhu, Y. et al. Single-atom in-doped subnanometer Pt nanowires for simultaneous hydrogen generation and biomass upgrading. Adv. Funct. Mater. 30, 2004310 (2020).

- $\mathrm{Pi}, \mathrm{Y}$. et al. Selective surface reconstruction of a defective iridium-based catalyst for high-efficiency water splitting. Adv. Funct. Mater. 30, 2004375 (2020).

- Zhuang, L. et al. Defect-induced Pt-Co-Se coordinated sites with highly asymmetrical electronic distribution for boosting oxygen-involving electrocatalysis. Adv. Mater. 31, 1805581 (2019).

- Lu, F. et al. Engineering platinum-oxygen dual catalytic sites via charge transfer towards high-efficient hydrogen evolution. Angew. Chem. Int. Ed. 59, 17712 (2020).

- Cheng, N. et al. Platinum single-atom and cluster catalysis of the hydrogen evolution reaction. Nat. Commun. 7, 13638 (2016).

- Sheng, W. et al. Non-precious metal electrocatalysts with high activity for hydrogen oxidation reaction in alkaline electrolytes. Energy Environ. Sci. 7, 1719-1724 (2014).

- Pan, Y. et al. Cobalt nickel phosphide nanoparticles decorated carbon nanotubes as advanced hybrid catalysts for hydrogen evolution. J. Mater. Chem. A 4, 14675-14686 (2016).

- She, Z. W, Kibsgaard, J., Dickens, C. F, Chorkendorff, I., Nørskov, J. K. \& Jaramillo, T. F. Combining theory and experiment in electrocatalysis: insights into materials design. Science 355, eaad4998 (2017).

- Lim, B. et al. Pd-Pt bimetallic nanodendrites with high activity for oxygen reduction. Science 324, 1302 (2009).

- Li, M. et al. Ultrafine Jagged platinum nanowires enable ultrahigh mass activity for the oxygen reduction reaction. Science 354, 1414 (2016).

- Kibsgaard, J. et al. Designing an improved transition metal phosphide catalyst for hydrogen evolution using experimental and theoretical trends. Energy Environ. Sci. 8, 3022-3029 (2015).

- Mahmood, J. et al. An efficient and pH-universal ruthenium-based catalyst for the hydrogen evolution reaction. Nat. Nanotech. 12, 441-446 (2017).

- Zhu, Y. et al. Unusual synergistic effect in layered Ruddlesden-Popper oxide enables ultrafast hydrogen evolution. Nat. Commun. 10, 149 (2019).

- Yang, Y. et al. O-coordinated W-Mo dual-atom catalyst for pH-universal electrocatalytic hydrogen evolution. Sci. Adv. 6, eaba6586 (2020).

- Zhou, Y. et al. Enhanced performance of in-plane transition metal dichalcogenides monolayers by configuring local atomic structures. Nat. Commun. 11, 2253 (2020). 
- Xiong, M. et al. In situ tuning of electronic structure of catalysts using controllable hydrogen spillover for enhanced selectivity. Nat. Commun. 11, 4773 (2020).

- Sha, X., Chen, L., Cooper, A. C., Pez, G. P \& Cheng, H. Hydrogen absorption and diffusion in bulk a$\mathrm{MoO}_{3}$. J. Phys. Chem. C113, 11399-11407 (2009).

- Marcinkowski, M. D. et al. Controlling a spillover pathway with the molecular cork effect. Nat. Mater. 12, 523-528 (2013).

- Shen, F. et al. Bimetallic iron-iridium alloy nanoparticles supported on nickel foam as highly efficient and stable catalyst for overall water splitting at large current density. Appl. Catal. B: Environ. 278, 119327 (2020).

- Tierney, H. L., Baber, A. E., Kitchin, J. R. \& Sykes, E. C. H. Hydrogen dissociation and spillover on individual isolated palladium atoms. Phys. Rev. Lett. 103, 246102 (2009).

- Baber, A. E., Tierney, H. L., Lawton, T. J. \& Sykes, E. C. H. An atomic-scale view of palladium alloys and their ability to dissociate molecular hydrogen. ChemCatChem 3, 607-614 (2011).

- Zhu, L. et al. A rhodium/silicon co-electrocatalyst design concept to surpass platinum hydrogen evolution activity at high overpotentials. Nat. Commun. 7, 12272 (2016).

- Cheng, Y., Lu, S., Liao, F., Liu, L., Li, Y. \& Shao, M. Rh/MoS 2 nanocomposite catalysts with Pt-like activity for hydrogen evolution reaction. Adv. Funct. Mater. 27, 1700359 (2017).

- Sheng, M. et al. Approaching the volcano top: iridium/silicon nanocomposites as efficient electrocatalysts for the hydrogen evolution reaction. ACS Nano 13, 2786-2794 (2019).

\section{Figures}

a

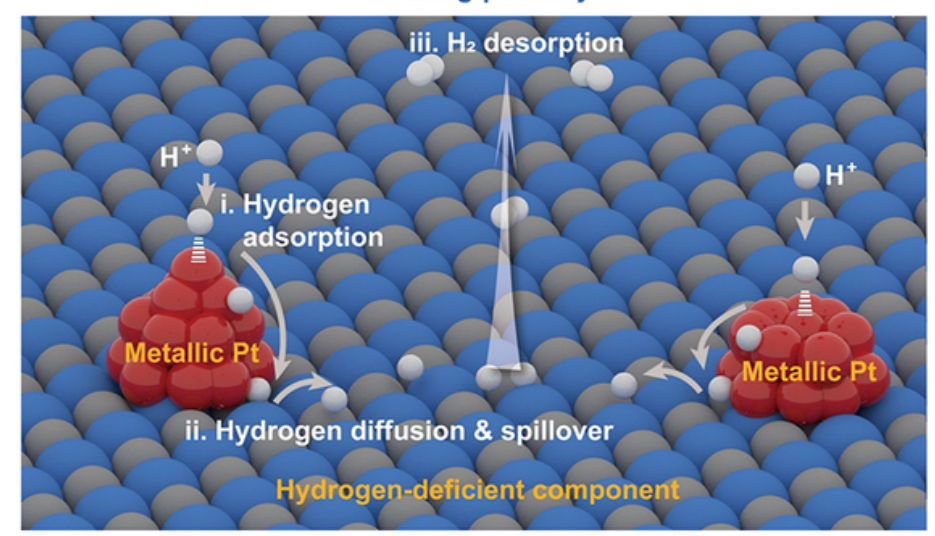

Hydrogen spillover-based binary-component catalyst (HSBCC)

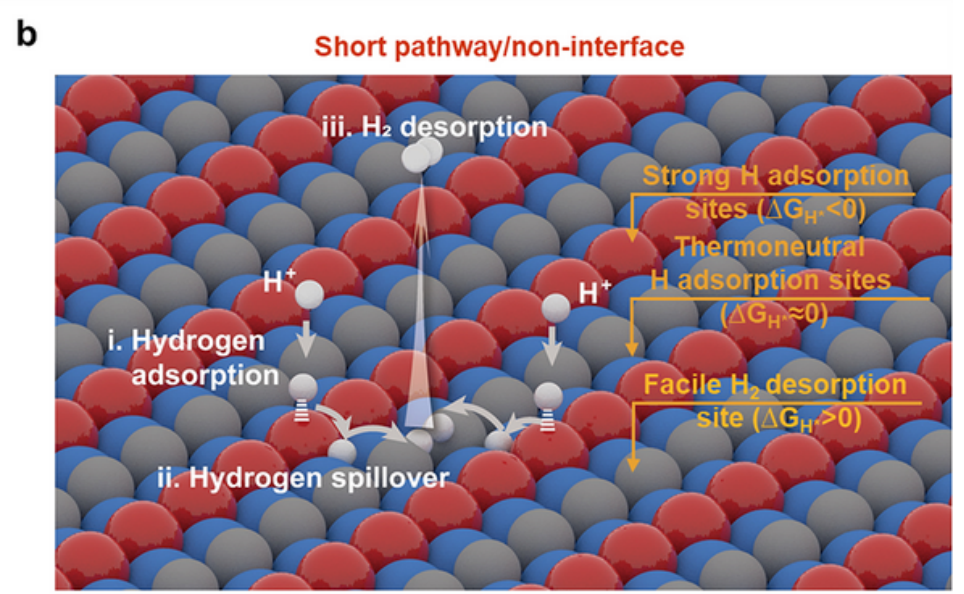

Hydrogen spillover-based single-component catalyst (HSSCC)

\section{Figure 1}

Schematic illustration of the hydrogen spillover on two-type catalyst systems for HER in acidic media. a, The conventional hydrogen spillover-based binary-component catalyst (HSBCC) system by coupling 
hydrogen-enriched Pt-based nanocrystals with hydrogen-deficient component. b, hydrogen spilloverbased single-component catalyst (HSSCC) system with atomic-level multiple catalytic sites.

a

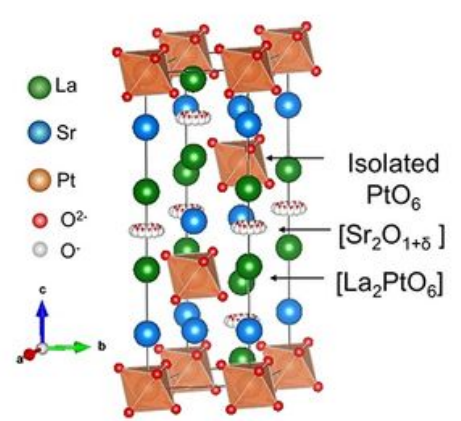

e

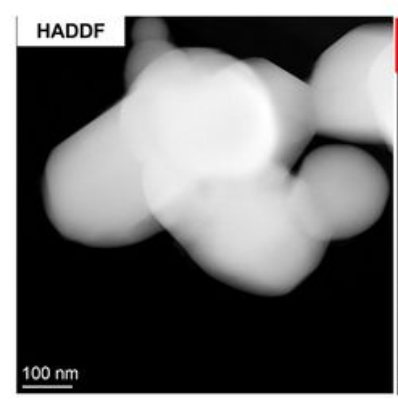

b

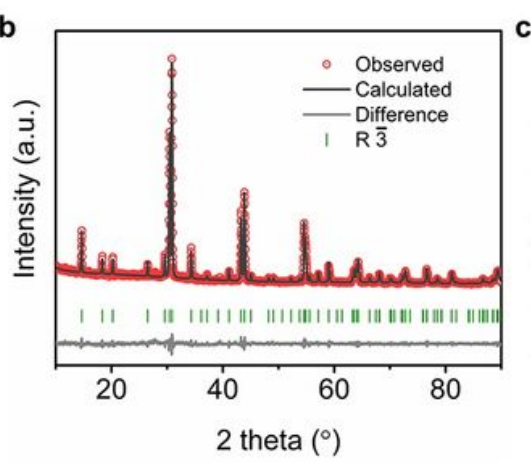

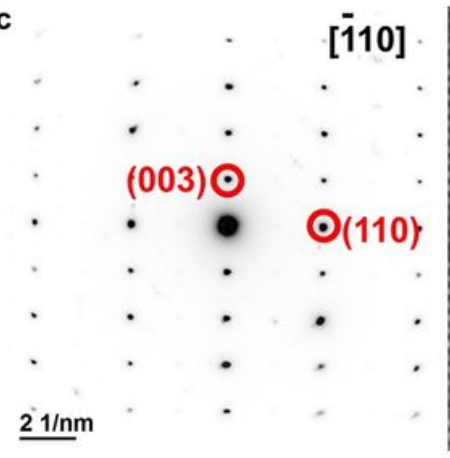
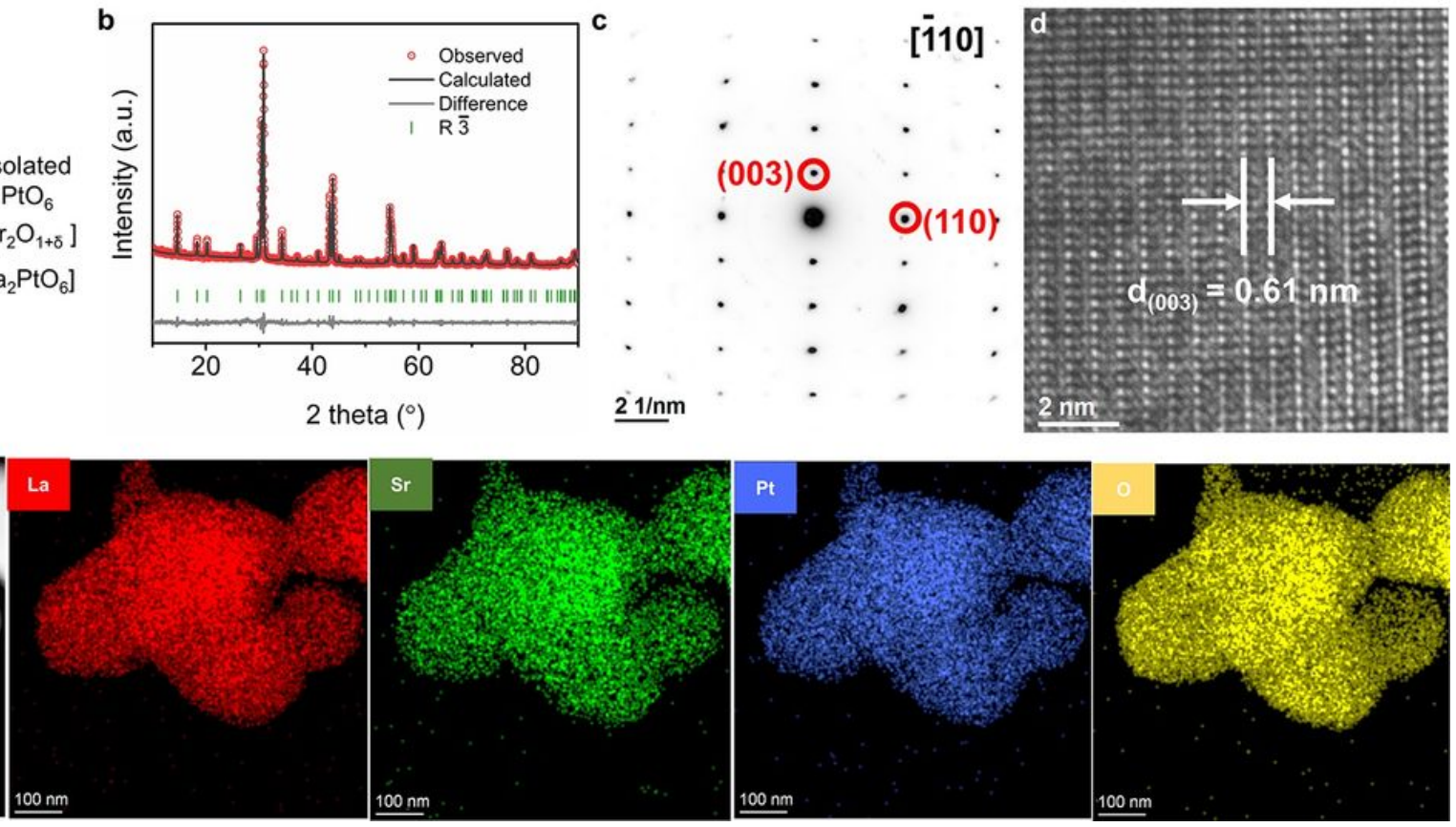

Figure 2

Crystal structure and morphology characterization. a, Refined XRD profile of La2Sr2PtO7+ס. b, Schematic presentation of La2Sr2Pt07+ $\delta$ structure. c, SAED pattern along the [-110] direction and d, the corresponding HRTEM image of La2Sr2PtO7+ס. e, HAADF-STEM and the corresponding elemental mapping images of La2Sr2PtO7+ $\delta$.

a

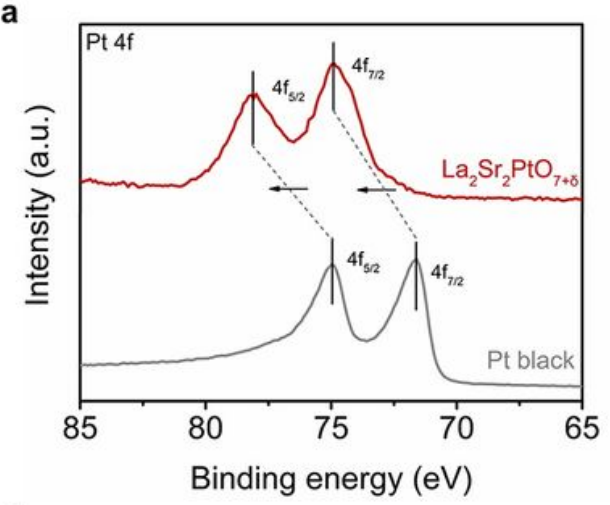

d

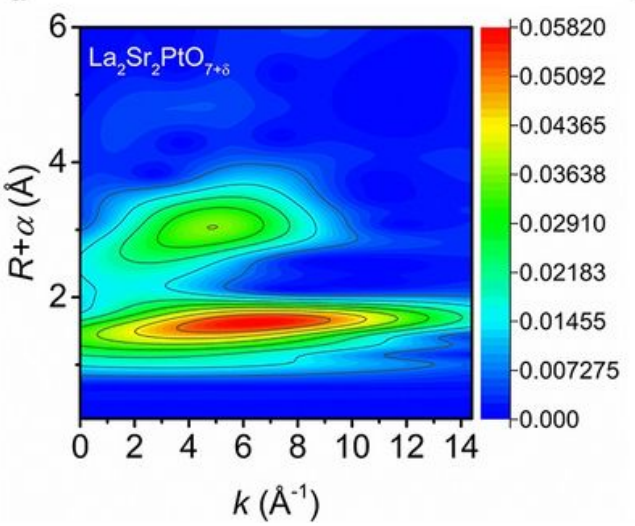

b
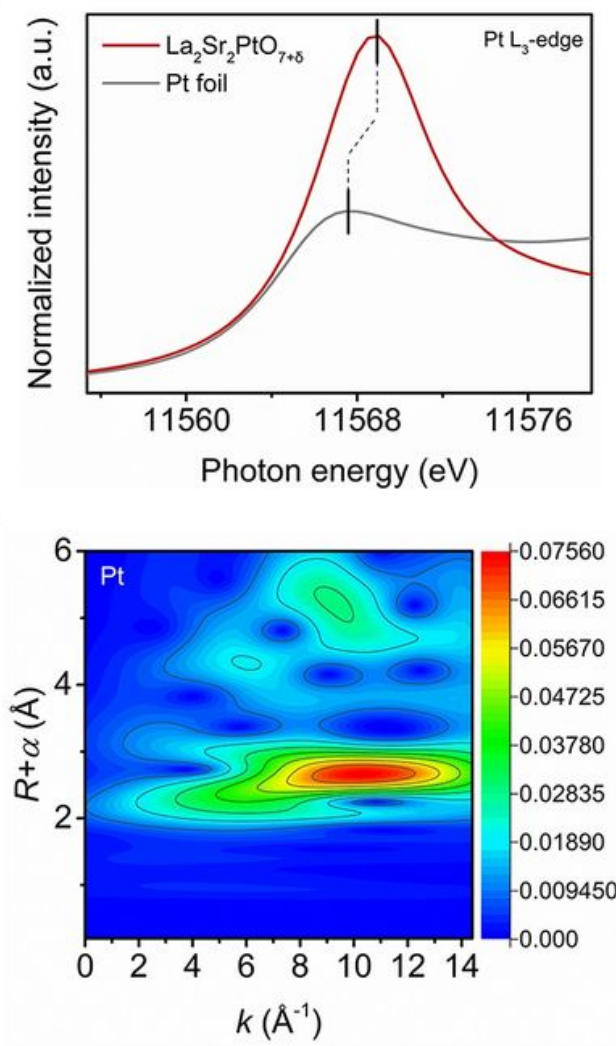

c

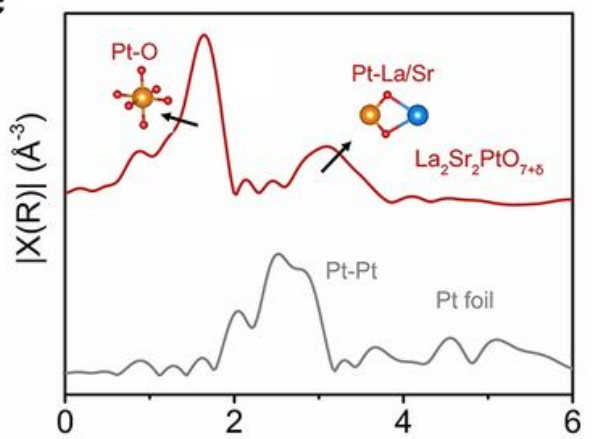

Radial distance $(\AA)$

f

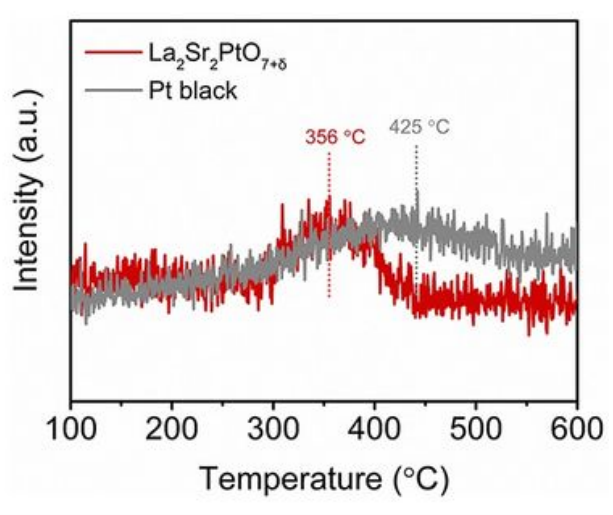




\section{Figure 3}

Electronic structure characterization. a, The high-resolution Pt $4 \mathrm{f}$ XPS spectra of La2Sr2Pt07+ $\delta$ and Pt black. b, Pt L3-edge XANES spectra and c, K3-weighted Fourier transform EXAFS spectra of the

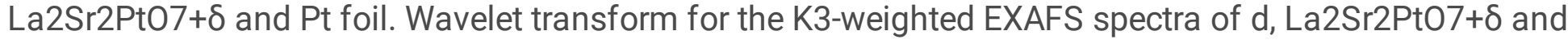
e, Pt foil. f, H2-TPD profiles of La2Sr2PtO7+ס and Pt black.

a

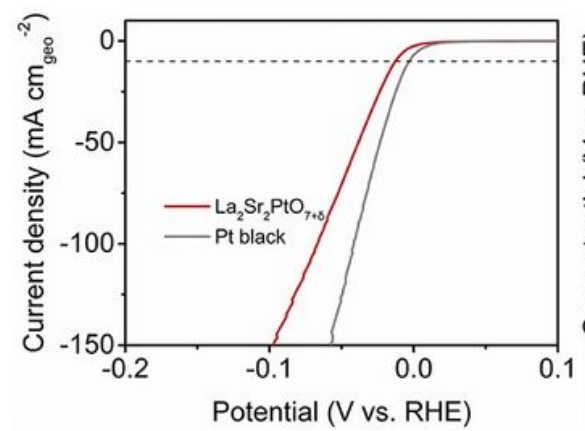

d

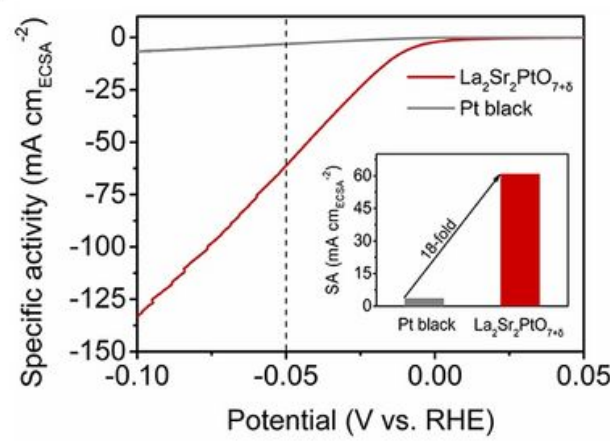

g

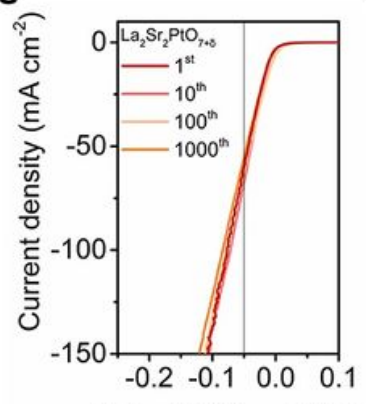

Potential (V vs. RHE) b

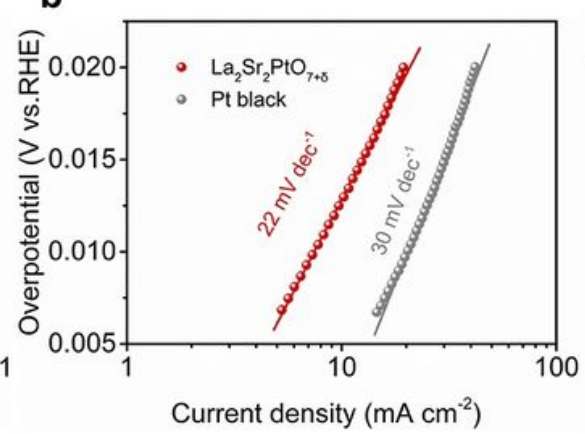

e

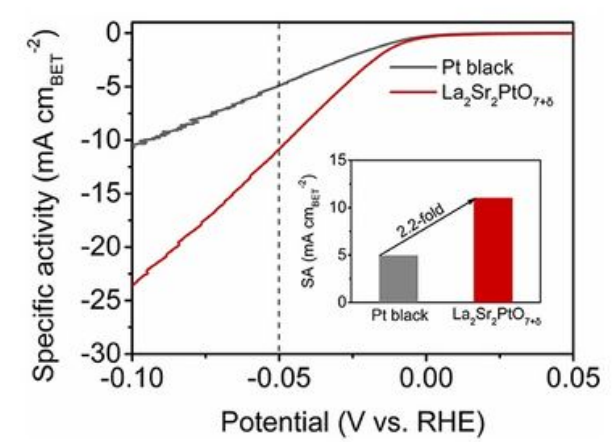

i

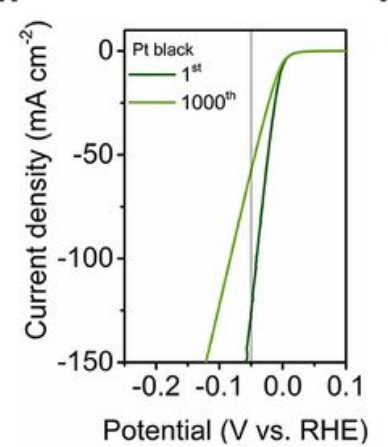

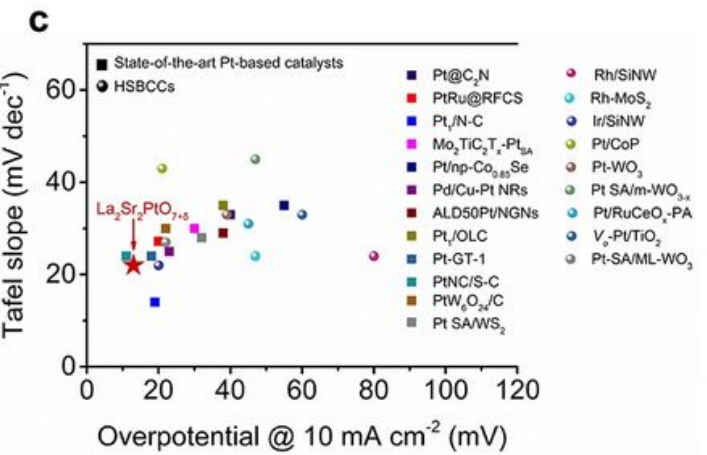

f

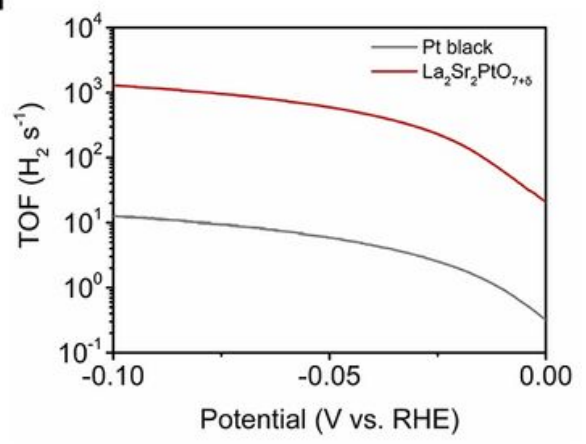

j

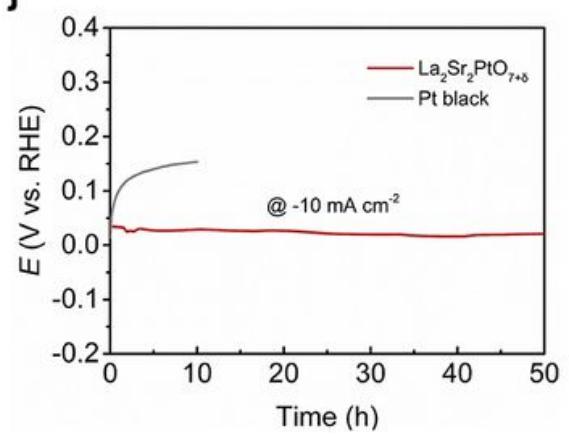

Figure 4

Electrocatalytic HER performance in acid. a, Polarization curves of La2Sr2PtO7+ $\delta$ and Pt black in an Arsaturated $0.5 \mathrm{M} \mathrm{H} 2 \mathrm{SO} 4$ solution with a scan rate of $5 \mathrm{mV} \mathrm{s}-1$. b, Tafel plots of La2Sr2PtO7+ $\delta$ and Pt black. c, HER activity comparison between La2Sr2PtO7+ $\delta$ and HSBCCs and other state-of-the-art Ptbased catalysts ever reported. Specific activity normalized to d, ECSA and e, RSA of La2Sr2PtO7+ $\delta$ and Pt black as a function of applied potential. Inset: specific activity at the overpotential of $\eta=0.05 \mathrm{~V}$. $\mathrm{f}$, The relationship between TOF and the tested potentials of La2Sr2PtO7+ $\delta$ and Pt black in $0.5 \mathrm{M} \mathrm{H} 2 \mathrm{SO} 4$ solution. g, Polarization curves of La2Sr2Pt07+ $\delta$ initially, as well as after 10,100, and 1000 cycles. h, Polarization curves of Pt black initially and after 1000 cycles. i, Current density comparison at $-0.05 \mathrm{~V}$ 
versus RHE initially and after 1000 cycles for La2Sr2Pt07+ $\delta$ and Pt black. j, Chronopotentiometry response of La2Sr2Pt07+ $\delta$ and Pt black at a constant cathodic current density of $10 \mathrm{~mA} \mathrm{~cm}-2$.

a

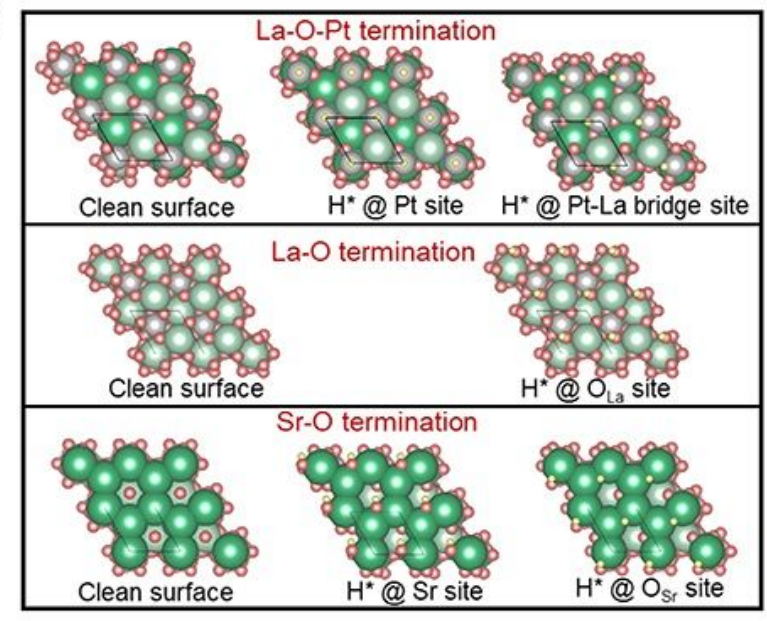

b

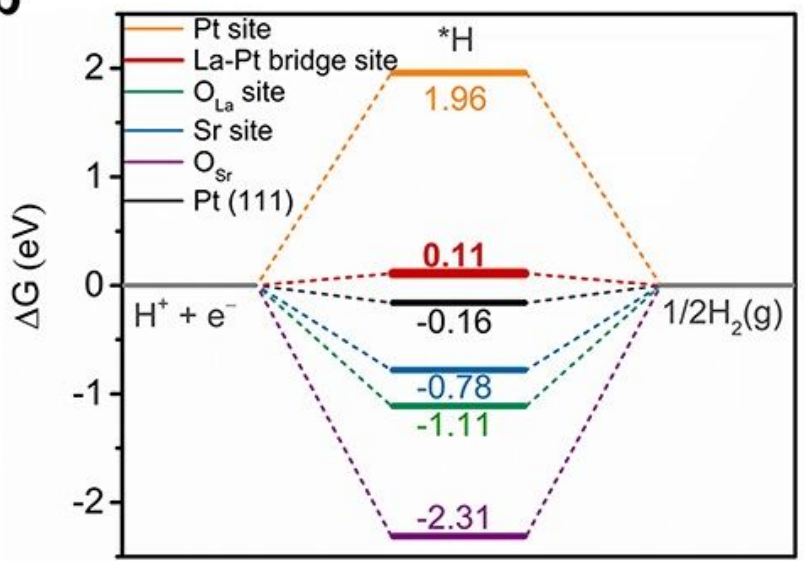

Reaction Coordinate

C

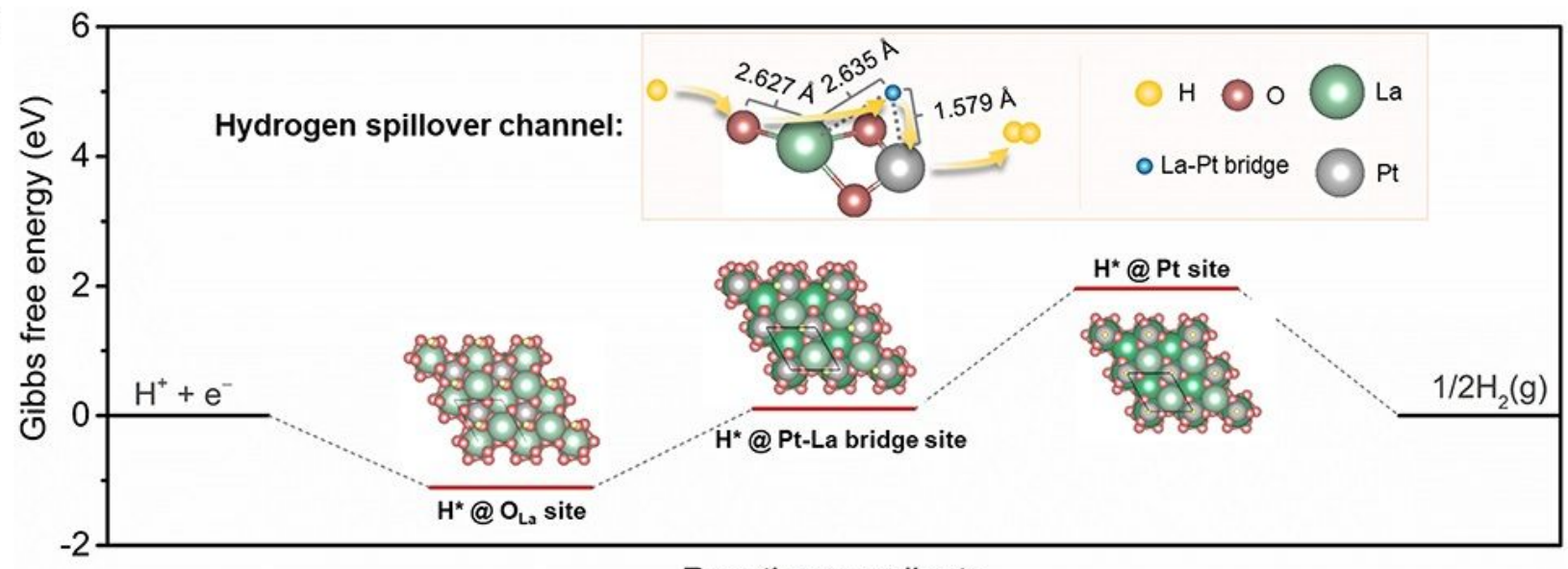

Reaction coordinate

d

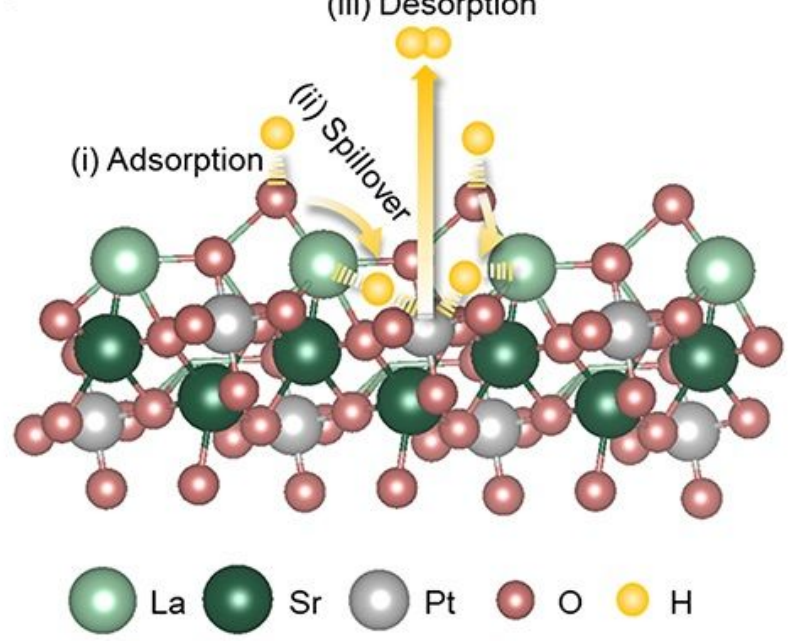

e

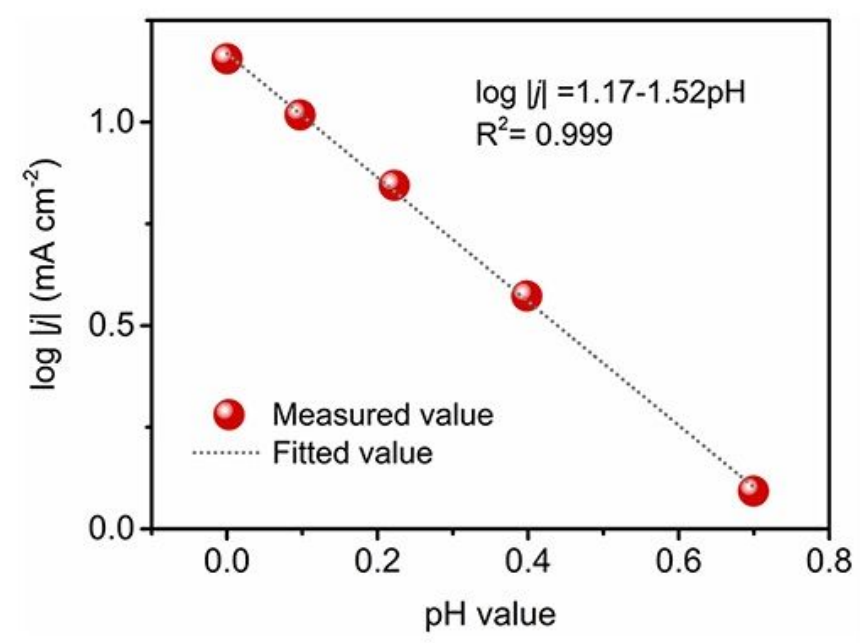

Figure 5

DFT calculations. a, (001) surface slab models with different terminations of La2Sr2PtO7+ $\delta$ and the optimized structures. The yellow, red, gray, light and dark green balls represent $\mathrm{H}, \mathrm{O}, \mathrm{Pt}, \mathrm{La}$ and $\mathrm{Sr}$, respectively. b, Gibbs free energy diagram for hydrogen adsorption at different catalytic sites on 
La2Sr2Pt07+ס and Pt (111). c, Calculated free energy diagram for hydrogen spillover pathway on $\mathrm{La} 2 \mathrm{Sr} 2 \mathrm{PtO}+\delta$. Insets are the optimized $\mathrm{H}^{*}$ adsorption structures at various sites and possible hydrogen spillover channel. d, Schematic illustration of catalysis mechanism for acidic HER via atomic-scale hydrogen spillover on the La2Sr2Pt07+ $\delta$ oxide. e, Liner plot of log ljl at $-0.03 \mathrm{~V}$ (vs. RHE) versus pH.

\section{Supplementary Files}

This is a list of supplementary files associated with this preprint. Click to download.

- Supprtinginformation.docx 